Documento No. 34

Algunos Aspectos de la Concentración en el Sistema Financiero Mexicano

por

Héctor E. González Méndez

Marzo, 1981.

Las ideas contenidas en el presente ensayo son responsabilidad exclusiva de los autores y no reflejan la posición del Banco de México, S.A. 


\section{ALGUNOS ASPECTOS DE LA CONCENTRACION \\ EN EL SISTEMA FINANCIERO MEXICANO}

por

Héctor E. González Méndez*

I. Introducción.

El sistema financiero mexicano se caracteriza por una rápida profundización de sus servicios dentro del sector real de la economía, junto a este proceso sin embargo se experimenta también una importante concentración de sus operaciones y recursos en un número reducido de establecimientos o grupos económico-financieros.

El proceso de la concentración financiera no puede considerarse, claro está, un aspecto exclusivo al caso de México; en un número muy considerable de países, la evolución de las operaciones financieras se ha visto acompañada también de una concentración de las mismas en unos cuantos agentes financieros.

Se presentan casos tan extremos como el de Israel; donde tres instituciones controlan el 90\% de los activos totales del sistema bancario y donde la evolución hacia la concentración ha sido acelerada. En países como España y Brasil la concentración se ha reforzado recientemente como resultado de los movimientos hacia sistemas de banca múltiple. En otros países no se ha podido evitar la concentración financiera no obstante la implantación de medidas y reglamentaciones encaminadas a propiciar una mayor competitividad dentro del sector, tal es el caso de Suiza, Alemania y Australia. Existen también casos de países con alta concentración de tipo estatal como son Francia e Italia; donde las autoridades buscan actualmente reorientar sus políticas hacia una mayor competencia entre las instituciones estatales y las privadas. Canadá y Japón acusan también la preponderancia dentro del sistema bancario de unas pocas instituciones y se advierte que las autoridades monetarias tienen poco interés en modificar tal situación. Por último, cabe mencionar el caso de los Estados Unidos de Norteamérica, el cual se aparta en alguna medida de los ejemplos anteriores ya que el $50 \%$ de los recursos totales del sistema se encuentra distribuido entre cincuenta instituciones financieras.

\footnotetext{
* Agradezco al C.P.T. David Franco y al Lic. Carlos Isoard su valiosa orientación en la obtención e interpretación de los datos utilizados en la primera parte de este trabajo. También agradezco la colaboración de Rocío Legarreta Fadrique, Ida García Azcué y Jorge Sardaneta. La mecanografía y corrección de gran parte de mis errores de redacción fueron realizados eficientemente pro Rosamaría Ramos.
} 
En suma, en una muestra de 16 países (en su mayoría altamente industrializados) se encontró que el promedio del número de instituciones grandes es de 8.5, mismas que controlan -también en promedio- el $47.3 \%$ del total de activos de los sistemas bancarios (ver cuadro 1), es decir, el panorama financiero del mundo occidental presenta una alta concentración de sus recursos en un número reducido de instituciones. La concentración promedio de la muestra de países se agudiza aún más si excluimos a tres de ellos -Estados Unidos, Inglaterra y Japón- obteniéndose un promedio de instituciones de 4.6 y un promedio de activos controlados de $46.1 \%$.

La intermediación financiera en México se realiza a través de; (1) los establecimientos bancarios, (2) el mercado organizado de valores, (3) las compañías de seguros y (4) las organizaciones auxiliares de crédito. No obstante que el número de intermediarios es amplio, el volumen total de recursos intermediados es amplio, el volumen total de recursos otorgado por el sector, consecuentemente es de esperarse que habremos de poner una mayor atención a las características que reviste la concentración de las actividades y los recursos bancarios. La naturaleza de la concentración financiera en el mercado bursátil, las compañías de seguros y fianzas así como en otras organizaciones auxiliares de crédito cobra particular relevancia al encontrar que dicha concentración está altamente asociada al grado de dependencia de estos subsectores financieros con las instituciones más fuertes del sistema bancario, en este sentido habrá de orientar el análisis de la concentración en el sector financiero no bancario.

En suma, la presente nota se divide en dos partes; la primera se ocupa de la concentración bancaria en sus operaciones activas y pasivas y distribución regional; la segunda vincula a la concentración que acusan los agentes financieros no bancarios con el grado de dependencia de éstos respecto a alguna institución bancaria. 
Cuadro 1

Niveles de concentración bancaria

\begin{tabular}{lcc}
\hline \multicolumn{1}{c}{ País } & $\begin{array}{c}\text { Número de } \\
\text { instituciones }\end{array}$ & $\begin{array}{c}\text { \% de los activos totales } \\
\text { del sistema bancario }\end{array}$ \\
\hline Alemania & 3 & 10 \\
Austria & 2 & 17.5 \\
Australia & 7 & 49.0 \\
Bélgica & 3 & 32 \\
Canadá & 5 & 62 \\
Corea & 5 & 50.7 \\
Dinamarca & 5 & 52 \\
España & 7 & 65 \\
Estados Unidos & 50 & 47 \\
Francia & 3 & 50 \\
Holanda & 3 & 41 \\
Inglaterra & 13 & 55.5 \\
Israel & 3 & 90 \\
Italia & 9 & 33 \\
Japón & 13 & 54 \\
Suiza & 5 & 48 \\
Promedio & 8.5 & 47.3 \\
\hline FUENTE: Oficina de Banca Central y Política Financiera Comparada & Banco de México
\end{tabular}

FUENTE: Oficina de Banca Central y Política Financiera Comparada. Banco de México

\section{Sistema Bancario.}

A. Consideraciones sobre la concentración de los recursos bancarios.

El número de establecimientos bancarios ha mantenido una marcada tendencia descendente durante las tres últimas décadas; en 1950 el sistema contaba con aproximadamente 248 instituciones de tipo bancario ${ }^{1 /}$, las cuales se han reducido a poco más de 100 al iniciarse la década de los ochentas. Paralelo a este proceso se ha observado que los recursos de unos cuantos bancos han crecido espectacularmente, mientras que la mayoría de las instituciones ha mantenido un ritmo de crecimiento atribuible sólo al crecimiento de la economía y a la reducción tan drástica en el número de establecimientos. Este proceso ha conducido a que el $75 \%$ de los recursos captados por los bancos haya pasado de la contabilidad de 42 establecimientos en 1950 a la contabilidad de solamente 6 establecimientos en 1979 (ver cuadro 2). Los cambios en el número y tamaño de las instituciones bancarias han ocasionado también que la posición de liderazgo que mantenía un solo banco en 1950

\footnotetext{
1/ Existen diferentes criterios de agrupación.
} 
haya sido sustituida por una situación de tipo oligopólitica al iniciarse los ochentas, donde poco más de 15 instituciones controlan aproximadamente el $90 \%$ del total de recursos del sistema y cuentan con 1 763 oficinas de un total de 2522 (1978), es decir, el 70\% de las oficinas bancarias pertenecen al 16\% de los bancos.

\section{Cuadro 2}

Instituciones del Sistema Bancario

\begin{tabular}{cccccc}
\hline $\begin{array}{c}\text { Por ciento } \\
\text { del total de } \\
\text { recursos* }\end{array}$ & 1950 & 1960 & 1970 & 1975 & 1979 \\
\hline $20 \%$ & 1 & 1 & 1 & 1 & 1 \\
$40 \%$ & 4 & 3 & 2 & 2 & 2 \\
$60 \%$ & 14 & 7 & 5 & 4 & 4 \\
$75 \%$ & 42 & 26 & 18 & 10 & 6 \\
$85 \%$ & - & - & - & 21 & 12 \\
T o t a 1 & 248 & 244 & 240 & 139 & 100 \\
\hline
\end{tabular}

* o proporción mayor de éstos.

Un método visual bastante popular en la medición de la concentración -sea ésta del ingreso, bancario o de otro tipo- es la elaboración de curvas de Lorenz, en la figura 1 se presenta una curva de esta naturaleza a partir de los datos correspondientes a 1978; en el eje vertical se incluye el número de bancos (en términos relativos) y en el eje horizontal el monto de la captación correspondiente (también en términos relativos). La interpretación que debe darse a la curva de Lorenz en esta caso es que la captación estará más concentrada en un número más reducido de bancos en tanto esta curva se acerque más al ángulo inferior derecho, la distribución equiproporcional de la captación entre los bancos está dada por la línea de 45 grados.

La concentración bancaria, medida a través del coeficiente de $\mathrm{GINI}^{1 /}$, ha sido particularmente acelerada durante la década de los setentas; dicho indicador pasó de 0.675 en 1950 a 0.72 3n 970 (4.5 centésimas en 20 años) y a 0.764 en 1978 (4.4 en menos de 10 años), es decir, la concentración medida a través de este indicador ha crecido en forma cada vez más acelerada.

\footnotetext{
1/ $\quad G=\frac{o^{100}[x-f(x) d x]}{1 / 2(100)^{2}}, \quad$ al tomarse sobre la curva de Lorenz.
} 
Curva de Lorenz

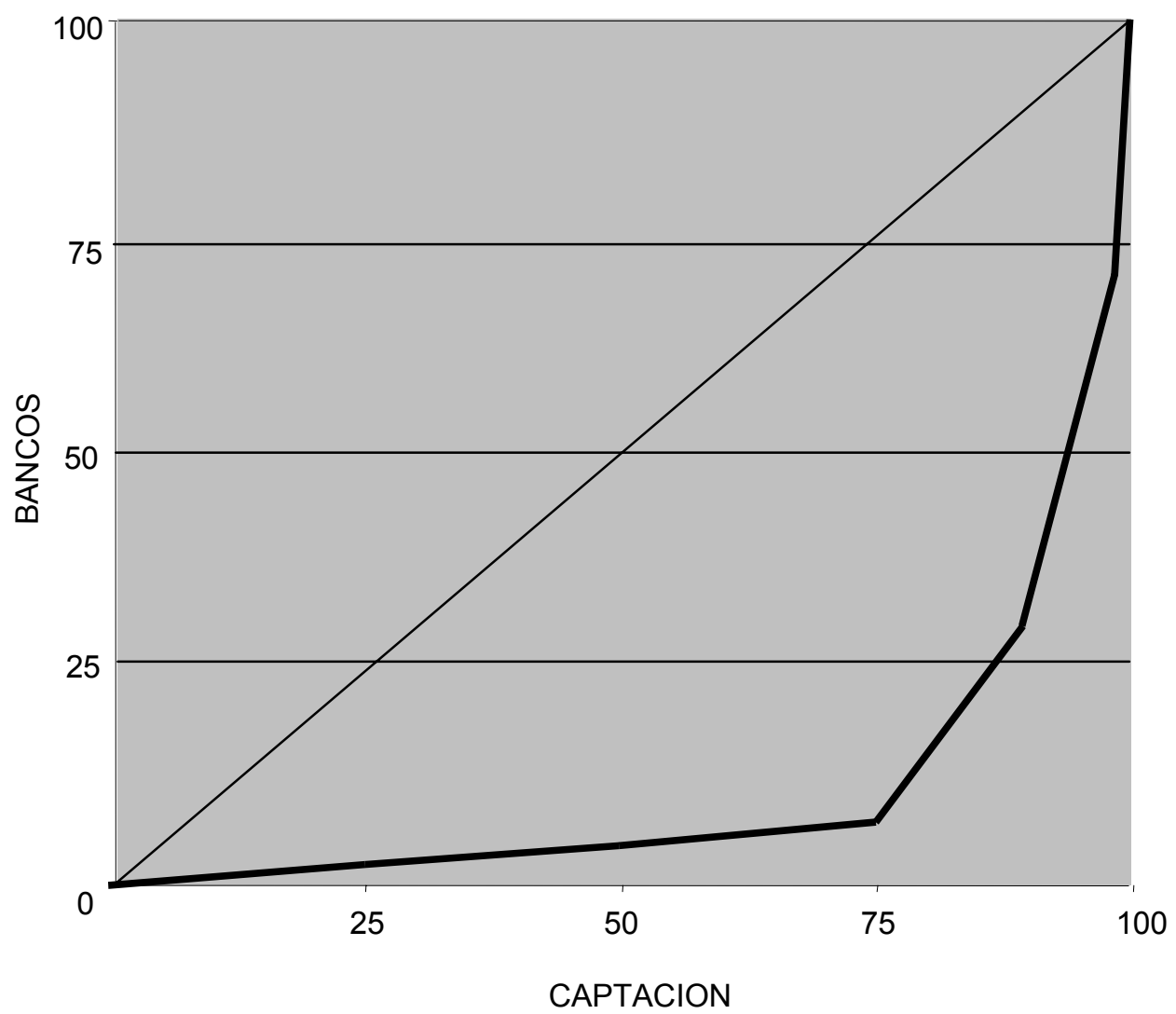

Por otra parte, el cálculo del índice de Miani-Calabrese $\mathrm{e}^{2 /}$ permite evaluar el grado de la concentración de las sucursales bancarias entre los diferentes grupos de tamaños de bancos. Los resultados de este indicador muestran muy poco cambio entre 1950 y 1978 ya que pasó de 0.846 a 0.840 , cambio que inclusive acusa una tendencia decreciente. El comportamiento que presenta el índice de MainiCalabrese se debe a que en 1950 había solamente un banco con más de 100 sucursales (particularmente en 1978 el número se eleva a 7 grandes bancos) y una mejor distribución de los bancos en los estratos que utiliza el índice, este comportamiento afecta al índice Miani-Calabrese en el sentido de que se reduce la ponderación predominante que asigna el indicador a un solo banco (el más grande). En el cuadro 3 se muestran los resultados del coeficiente de GINI y del índice de Miani-Calabrese.

2) $\quad R_{M C}=\frac{1-\sum_{g=1}^{n}\left[\frac{m g}{m .} x \frac{S g}{S .}\right]}{(100)^{2}}$

donde $\mathrm{m}$ representa el número de matrices bancarias y $\mathrm{S}$ el número de sucursales, el subíndice $\mathrm{g}$ se emplea como contador de grupos o clases. 
Cuadro 3

Indices de Concentración Bancaria

\begin{tabular}{cccc}
\hline \multirow{2}{*}{0} & \multicolumn{2}{c}{ GINI $(\mathrm{G})$} & \\
\cline { 2 - 3 } & Valor & Tasa de Cambio & MIANI-CALABRESE (R) \\
\hline 1950 & 0.675 & $2.9 \%$ & 0.8460 \\
1955 & & & 0.8324 \\
1960 & 0.695 & $3.6 \%$ & 0.8325 \\
1965 & & & 0.8373 \\
1970 & 0.720 & & 0.8422 \\
1975 & & $6.1 \%$ & 0.8405 \\
1976 & & & 0.8472 \\
1978 & 0.764 & & 0.8401 \\
\hline
\end{tabular}

Las conclusiones que se derivan del coeficiente de GINI y del índice de MIANI-CALABRESE podrían parecer contradictorias a primera vista, sin embargo, no es así. El comportamiento del primero está señalando que la importancia relativa de un reducido número de bancos es cada día mayor, mientras que el comportamiento del segundo establece que la posición única del Banco Nacional de México, S.A. en 1950 es ahora equiparable al de otras instituciones de igual importancia; lo cual atenúa la importancia relativa de los bancos dentro de su clase, pero acentúa la posición oligopólica de un número reducido de grandes bancos.

La marcada tendencia que acusan los sistemas financieros hacia la concentración ha sido atribuida en numerosos estudios a la tendencia decreciente de los costos unitarios asociados a la escala de operación. Autores tales como George J.Benston, D. A. Alhadeff, F. W. Bell, Schweiger y McGee han encontrado que distintos segmentos o departamentos del sistema financiero americano presentan marcadas economías de escala, lo cual podría haber favorecido la concentración de recursos en bancos más grandes de bajo costo unitario. La presencia de economías de escala en Estados Unidos de Norteamérica y el hecho de que éstas propicien la concentración no está en contradicción con el bajo grado de concentración de que se hacía alusión al principio de esta nota en relación a ese país, en el caso americano se debe tomar en cuenta la legislación bancaria ha sido un serio impedimento a la formación de grandes bancos que operen en toda la Unión Americana.

Los trabajos elaborados sobre el comportamiento de los costos de las instituciones bancarias en México revelan que el sistema sí está sujeto a economías de escala, pero que sin embargo, dichas economías de escala no se presentan a todo lo largo del espectro bancario; la tendencia decreciente de 
los costos asociados al tamaño de la operación bancaria alcanza su nivel más bajo a una escala inferior a la que actualmente operan las cuatro instituciones más grandes del país.

Dado que en esta nota no se intenta profundizar sobre la naturaleza y característica de las economías de escala del sistema bancario mexicano, solamente habremos de valernos de resultados y conclusiones de otros trabajos sobre el tema ${ }^{1}$. En el cuadro 4 aparece un resumen representativo de los niveles de costo unitario y los rendimientos de capital de los bancos, como ahí se puede apreciar los bancos más grandes del sistema obtienen rendimientos bastante elevados en comparación con otros bancos (cuasi-rentas). Sin embargo, dichos beneficios no parecen estar asociados con niveles más bajos de costos. Los bancos listados en el tercer grupo me que aparece en el cuadro 4 reportaron costos y rendimientos inferiores al resto de los grupos, algunos de estos bancos presentan actualmente (en términos muy generales) condiciones de operación e integración que ilustran las condiciones por las que atravesaron los dos bancos más grandes del sistema (particularmente el de más reciente consolidación como tal) durante la segunda mitad de los cincuentas y la década de los sesentas.

Cuadro 4. Indicadores de Costo y Rendimiento Bancario 1978

\begin{tabular}{|c|c|c|}
\hline Instituciones $^{+}$ & $\begin{array}{c}\text { Costo Total } \\
\text { por Peso } \\
\text { Captado* }\end{array}$ & $\frac{\text { Ingresos Netos }}{\text { Cap. }+ \text { Rvas. }}(\%)$ \\
\hline I. Los dos bancos más grandes & 17.407 & 38.95 \\
\hline $\begin{array}{l}\text { II. Dos bancos grandes }\left(3^{\circ} \text { y } 4^{\circ} \text { lugar en }\right. \\
\text { escala) }\end{array}$ & 17.225 & 27.87 \\
\hline III. Seis bancos medianos & 14.936 & 17.31 \\
\hline $\begin{array}{l}\text { IV. RESTO (Promedio no ponderado entre } \\
7 \text { grupos)** }\end{array}$ & 21.594 & 21.44 \\
\hline
\end{tabular}

Al parecer, las dos instituciones más grandes supieron incorporar las economías de escala propias de la industria dentro de sus procesos productivos durante casi dos décadas, alcanzando de esta manera una supremacía en el mercado que actualmente -no obstante que han agotado sus economías de escala- les coloca en una posición en la que su producto bancario está altamente diferenciado del resto y así derivan sus cuasi-rentas. Es claro que la variedad y características de los servicios financieros

\footnotetext{
1/ Economías de Escala y Concentración Bancaria.- El caso de México por Héctor E. González Méndez. Serie de Documentos de Investigación No. 29. Subdirección de Investigación Económica. Banco de México, S.A.
} 
que ofrecen estos dos grandes bancos han sido hasta la fecha un producto (paquete) muy diferente del resto del sistema, sin embargo, con el advenimiento de la banca múltiple en 1976, otras instituciones han escalado (o están en el proceso de lograrlo) a este nivel amplio de servicios financieros y habrán de afectar, consecuentemente dichas cuasi-rentas.

B. Consideraciones sobre las operaciones activas de las instituciones bancarias y concentración del crédito.

El sistema de banca múltiple -integrado por 30 instituciones en diciembre de 1979- acusa una elevada concentración del crédito; en un extremo, el 95.2\% de los usuarios (los más pequeños) recibieron el 32.4\% del crédito, mientras que en el extremo opuesto, el $0.4 \%$ de los usuarios (los más grandes) recibieron el $38.6 \%$ del crédito. Una descripción más detalladas de la distribución del crédito bancario aparece en el cuadro 5; como ahí se puede observar, el crédito bancario no está igualmente concentrado en todas las instituciones del sistema. Los bancos medianos son los que presentan un grado mayor de concentración (estos mismos bancos son los que aparecen en el grupo de más bajo costos del apartado anterior); por un lado otorgan el $11 \%$ del crédito al $89.2 \%$ de los usuarios y por otro lado, el $62.5 \%$ del crédito al 1.8\% de los acreditados. El comportamiento individual de las instituciones bancarias en relación a la concentración de sus operaciones activas se estimó a través del índice de concentración del crédito (ICC) ${ }^{1}$, , los resultados se muestran en el cuadro 6 .

$$
\begin{gathered}
\text { 1/ } I C C=\frac{\sum_{i=1}^{n}\left(\frac{I C_{i}}{C T}\right)^{2}}{\sum_{i=1}^{n}\left(\frac{I C_{i}}{C T}\right)\left(\frac{I U_{i}}{T U}\right)} \\
\text { donde } 1 \leq \mathrm{ICC} \leq \alpha \\
C T=\sum_{i=1}^{n} I C_{i} \\
T U=\sum_{i=1}^{n} I U_{i} \\
\text { IC }- \text { Intervalo de Crédito } \\
\text { IU - Intervalo de Usuarios }
\end{gathered}
$$


Cuadro 5

Distribución del crédito entre acreditados y por tamaño de bancos

Millones de Pesos

1979

\begin{tabular}{lcccccc}
\hline & \multicolumn{2}{c}{ De 101 a 5 } & \multicolumn{2}{c}{ De 5.001 a 50 } & \multicolumn{2}{c}{ Más de 50 } \\
\cline { 2 - 7 } & $\mathrm{A}$ & $\mathrm{B}$ & $\mathrm{A}$ & $\mathrm{B}$ & $\mathrm{A}$ & $\mathrm{B}$ \\
& $\%$ & $\%$ & $\%$ & $\%$ & $\%$ & $\%$ \\
\hline I. Dos bancos (los más grandes) & 95.5 & 31.95 & 4.0 & 25.6 & 0.5 & 42.45 \\
II. Dos bancos & 95.2 & 29.1 & 4.2 & 26.2 & 0.6 & 44.65 \\
III. Dos bancos & 89.2 & 11.0 & 8.9 & 26.5 & 1.8 & 62.5 \\
IV. Cuatro bancos & 95.7 & 41.6 & 3.9 & 37.5 & 0.35 & 20.92 \\
V. Cuatro bancos & 94.6 & 45.3 & 5.2 & 38.9 & 0.2 & 15.7 \\
VI. Diez bancos & 94.9 & 49.2 & 4.8 & 37.4 & 0.3 & 13.4 \\
VII. Seis bancos (los más pequeños) & 92.73 & 51.06 & 6.8 & 40.9 & 0.4 & 8.04 \\
C O N S O L I D A D O & 95.2 & 32.4 & 4.4 & 29.0 & 0.4 & 38.6 \\
\hline
\end{tabular}

Notas: A - Usuarios

B - Crédito

* Los bancos integran los grupos están ordenados del mayor tamaño al menor.

\section{Cuadro 6}

Concentración del crédito bancario

\begin{tabular}{rrr}
\hline Bancos & $\begin{array}{c}\text { Indice de } \\
\text { Concentración }\end{array}$ & $\begin{array}{c}\text { Monto crédito promedio } \\
\text { (Miles de pesos) }\end{array}$ \\
I & 5.1370 & 1882.3 \\
III & 5.1890 & 2155.9 \\
V & 6.1785 & 2215.1 \\
VI & 8.7658 & 1077.7 \\
VII & 10.1285 & 5612.4 \\
VIII & 4.0838 & 5229.1 \\
IX & 3.5530 & 1672.8 \\
X & 4.4750 & 1188.1 \\
XI & 4.1028 & 1446.6 \\
XII & 3.8451 & 1583.4 \\
XIII & 3.8616 & 1983.5 \\
XIV & 3.3028 & 1513.4 \\
XV & 3.1526 & 1367.5 \\
XVI & 3.2872 & 1067.9 \\
XVII & 7.0065 & 4658.8 \\
XVIII & 4.1257 & 1686.3 \\
XIX & 2.8884 & 1846.7 \\
XX & 3.0207 & 1094.6 \\
XXI & 2.4518 & 796.9 \\
XXII & 2.9818 & 1390.3 \\
XXIII & 2.6590 & 924.7 \\
XXIV & 3.6265 & 1394.6 \\
XXV & 2.7759 & 1004.1 \\
XXVI & 2.5876 & 4062.7 \\
XXVII & 2.5405 & 851.1 \\
XXVIII & 3.3574 & 1291.7 \\
XXIX & 3.5018 & 895.7 \\
XXX & 4.8316 & 4523.4 \\
& 2.1453 & 642.0 \\
CONSOLIDADO & 5.1429 & 1954.7 \\
\hline
\end{tabular}


Las causas que propician la concentración del crédito pueden ser muchas y cambiar radicalmente de una institución a otra, por ejemplo, resulta interesante observar que las dos instituciones con los índices más altos de concentración son estatales. Sobre el particular se podría elaborar con amplitud, sin embargo, en lugar de recurrir al análisis de casos, se optó por un método de detección de variables significativas en la explicación del comportamiento del ICC a través del análisis de regresión. El grado de correlación entre algunas variables bancarias y el Indice de Concentración del Crédito permiten establecer a nivel de hipótesis relaciones de causalidad.

En primer lugar fue necesario incluir en el análisis aquellas variables estructurales que condicionan en gran medida el monto de las operaciones crediticias. Es fácil intuir en primera instancia, que las demandas de crédito de las personas morales serán en el promedio mayores que las correspondientes a las personas físicas. Del mismo modo, se pensó que es probable que el monto promedio del crédito otorgado al sector público difiera del monto promedio otorgado al sector privado. A fin de incorporar el impacto de estos aspectos estructurales del crédito en el nivel de la concentración, se definieron las variables correspondientes; $\mathrm{P}=$ (monto del crédito otorgado a personas físicas/monto del crédito otorgado a personas morales) y $\mathrm{S}=$ (monto del crédito destinado al sector privado/monto del crédito destinado al sector público).

El giro de las actividades agropecuarias, industriales o comerciales no es necesariamente el mismo; es difícil imaginar un complejo agropecuario, por ejemplo; que requiera un monto de inversión semejante a un complejo industrial - acero. En base a esta hipótesis se definieron las variables $\mathrm{A}_{1}, \mathrm{~A}_{2}$, y $\mathrm{A}_{3}$ que representan la distribución relativa del crédito bancario entre sectores económicos.

Toda operación de crédito lleva consigo un cierto grado de riesgo, las preferencias de los bancos a este factor influyen sobre la distribución de su cartera activa. A fin de medir el impacto que sobre la concentración del crédito tienen las preferencias al riesgo de los bancos se definió una variable proxi utilizando los saldos en la cuenta de cartera vencida, es decir, $\mathrm{R}=$ (cartera vencida/crédito) ${ }^{2}$.

La participación de los bancos dentro de un grupo económico puede influir considerablemente sobre la política de asignación puede influir considerablemente sobre la política de asignación de su cartera activa. La disponibilidad de crédito oportuno y en los montos requeridos por las empresas del grupo bien puede representar un objetivo prioritario a las utilidades del banco filial. Este tipo de consideraciones nos lleva a establecer la siguiente hipótesis; la concentración del crédito de un banco 
en unas cuantas empresas o personas de su grupo repercute ya sea o en las utilidades o en el diferencial entre sus tasas implícitas activa y pasiva. La rentabilidad por peso captado se definió como la variable $r_{\pi}$ y el diferencial entre tasas implícitas como la variable $\left(r_{a}-r_{p}\right)$.

Finalmente fue necesario definir una variable que incorpore en el análisis la asociación que puede existir entre la escala de operación del banco y la escala promedio de sus operaciones activas. La participación relativa de cada banco en el monto total del crédito que otorga el sistema se definió como la variable E.

Los resultados de los análisis de regresión se muestran en el cuadro 7. Todos los modelos se corrieron en los logaritmos de las variables con el fin de conocer la velocidad de cambio del ICC respecto a las tasas en que fueron definidas las variables independientes. Las elasticidades entre el Indice de Concentración del Crédito y las variables independientes se obtienen indirectamente a través de la interpretación del coeficiente correspondiente. En general, los resultados que aparecen en los modelos de regresión presentan los signos esperados y solamente el coeficiente de la variable de clasificación entre personas físicas y personas morales no resultó ser estadísticamente significativo en ninguno de los casos (modelos).

La capacidad de los modelos de regresión para explicar el comportamiento del ICC fluctúa entre el $78.97 \%$ y el $81.52 \%$, es decir, el índice de concentración bancaria del crédito está altamente correlacionado con; el tamaño de la institución que lo otorga, las preferencias de éstas al riesgo, el margen de intermediación en que operan y la forma en que distribuyen su crédito entre personas físicas morales y empresas estatales y privadas. Las variables cuya influencia es más clara en la concentración son:

1) La escala de operación bancaria; mientras mayor es la institución mayor es el coeficiente de concentración -otras cosas constantes-.

2) La distribución del crédito entre el sector público y el sector privado; mientras mayor es la participación del Estado en el uso del crédito, mayor es la concentración del mismo. Los ICC's de dos bancos medianos, dado su carácter de banca nacional, deben estar altamente influenciados por esta variable. 
Cuadro 7. Resumen de Resultados de los Modelos de Regresión del Indice de Concentración del Centro

(Análisis de Corte Transversal)

\begin{tabular}{|c|c|c|c|c|c|c|c|c|c|c|c|c|c|c|}
\hline \multirow[b]{2}{*}{ Evaluación } & \multicolumn{11}{|c|}{ Variables Independientes } & \multicolumn{3}{|c|}{ Estadísticas } \\
\hline & $\mathrm{C}$ & $\mathrm{E}$ & $\mathrm{R}$ & $\mathrm{S}$ & $\left(r_{a}-r_{p}\right)$ & $\mathrm{r}_{\pi}$ & $\mathrm{A}_{1}$ & $\mathrm{~A}_{2}$ & $\mathrm{~A}_{3}$ & $\mathrm{P}$ & $\pi$ & $\mathrm{R}^{2}$ & $\mathrm{e}$ & D-W. \\
\hline $\mathrm{I}$ & $\begin{array}{l}1.3286 \\
(5.09)\end{array}$ & $\begin{array}{l}0.1187 \\
(2.80)\end{array}$ & $\begin{array}{c}-0.0233 \\
(-0.56)\end{array}$ & $\begin{array}{c}-0.1300 \\
(-4.35)\end{array}$ & $\begin{array}{c}-0.4520 \\
(-2.33)\end{array}$ & & & & & $\begin{array}{c}-0.0810 \\
(-0.60)\end{array}$ & $\begin{array}{c}-0.5061 \\
(-0.87)\end{array}$ & 0.790 & 0.0804 & 2.111 \\
\hline II & $\begin{array}{l}1.2509 \\
(4.56)\end{array}$ & $\begin{array}{c}0.0880 \\
(3.41)\end{array}$ & & $\begin{array}{c}-0.1489 \\
(-5.14)\end{array}$ & $\begin{array}{c}-0.3576 \\
(-1.73)\end{array}$ & $\begin{array}{c}-0.0298 \\
(-0.66)\end{array}$ & & & & $\begin{array}{c}-0.1036 \\
(00.78)\end{array}$ & & 0.807 & 0.0774 & 1.989 \\
\hline III & $\begin{array}{l}1.2046 \\
(4.37)\end{array}$ & $\begin{array}{c}0.0939 \\
(2.57)\end{array}$ & & $\begin{array}{c}-0.1464 \\
(-5.10)\end{array}$ & $\begin{array}{c}-0.3223 \\
(-1.58)\end{array}$ & $\begin{array}{c}-0.0277 \\
(-0.45)\end{array}$ & & & $\begin{array}{c}-0.0259 \\
(-0.91)\end{array}$ & $\begin{array}{c}-0.1517 \\
(-1.06)\end{array}$ & & 0.813 & 0.0763 & 2.030 \\
\hline IV & $\begin{array}{l}1.2731 \\
(4.38)\end{array}$ & $\begin{array}{c}0.1185 \\
(2.77)\end{array}$ & $\begin{array}{c}-0.0065 \\
(-0.12)\end{array}$ & $\begin{array}{c}-0.1255 \\
(-3.81)\end{array}$ & $\begin{array}{l}.0 .3901 \\
(-1.76)\end{array}$ & & $\begin{array}{c}-0.0194 \\
(-0.53)\end{array}$ & & & $\begin{array}{c}-0.1073 \\
(-0.74)\end{array}$ & $\begin{array}{c}-0.0456 \\
(-0.75)\end{array}$ & 0.795 & 0.0818 & 2.121 \\
\hline $\mathrm{V}$ & $\begin{array}{l}1.2040 \\
(4.43)\end{array}$ & $\begin{array}{c}0.0955 \\
(2.53)\end{array}$ & & $\begin{array}{c}-0.1459 \\
(-5.11)\end{array}$ & $\begin{array}{c}-0.3129 \\
(-1.54)\end{array}$ & $\begin{array}{l}-0.272 \\
(-0.44)\end{array}$ & & $\begin{array}{c}-0.0329 \\
(-1.05)\end{array}$ & & $\begin{array}{c}-0.1661 \\
(-1.15)\end{array}$ & & 0.815 & 0.0759 & 2.040 \\
\hline VI & $\begin{array}{l}1.2147 \\
(4.41)\end{array}$ & $\begin{array}{c}0.9025 \\
(2.53)\end{array}$ & $\begin{array}{c}0.1387 \\
(-.99)\end{array}$ & $\begin{array}{c}-0.1470 \\
(-5.11)\end{array}$ & $\begin{array}{c}-0.3268 \\
(-1.58)\end{array}$ & $\begin{array}{c}-0.0288 \\
(-.46)\end{array}$ & $\begin{array}{c}-0.0212 \\
(-0.81)\end{array}$ & & & & & 0.811 & 0.077 & 2.023 \\
\hline VII & $\begin{array}{l}1.0628 \\
(4.42)\end{array}$ & $\begin{array}{c}0.0965 \\
(2.59)\end{array}$ & & $\begin{array}{c}-0.1342 \\
(-4.87)\end{array}$ & $\begin{array}{c}-0.2814 \\
(-1.41)\end{array}$ & $\begin{array}{c}-0.0347 \\
(-0.56)\end{array}$ & $\begin{array}{c}-0.0139 \\
(-0.54)\end{array}$ & & & & & 0.803 & 0.0765 & 2.0153 \\
\hline VIII & $\begin{array}{l}1.1810 \\
(4.58)\end{array}$ & $\begin{array}{c}0.1183 \\
(2.76)\end{array}$ & $\begin{array}{l}0.0074 \\
(-0.14)\end{array}$ & $\begin{array}{c}-0.1167 \\
(-3.72)\end{array}$ & $\begin{array}{c}-0.3705 \\
(-1.66)\end{array}$ & & & $\begin{array}{c}-0.0103 \\
(-0.30)\end{array}$ & & & & 0.789 & 0.0809 & 2.097 \\
\hline IX & $\begin{array}{l}1.1022 \\
(4.35)\end{array}$ & $\begin{array}{c}0.1183 \\
(2.76)\end{array}$ & $\begin{array}{c}-0.0042 \\
(-0.08)\end{array}$ & $\begin{array}{c}-0.1164 \\
(3.71)\end{array}$ & $\begin{array}{c}-0.3572 \\
(-1.60)\end{array}$ & $\begin{array}{c}-0.0482 \\
(-0.72)\end{array}$ & $\begin{array}{c}-0.0136 \\
(-0.40)\end{array}$ & & & & $\begin{array}{c}-0.0442 \\
(0.74)\end{array}$ & 0.789 & 0.081 & 2.104 \\
\hline $\mathrm{X}$ & $\begin{array}{l}1.1851 \\
(4.07)\end{array}$ & $\begin{array}{c}0.1148 \\
(2.81)\end{array}$ & $\begin{array}{c}-0.0028 \\
(-0.05)\end{array}$ & $\begin{array}{c}-0.1240 \\
(-3.75)\end{array}$ & $\begin{array}{c}-0.3761 \\
(-1.63)\end{array}$ & $\begin{array}{c}-0.0438 \\
(-0.65)\end{array}$ & $\begin{array}{c}-0.0218 \\
(-0.60)\end{array}$ & & $\begin{array}{c}-0.0943 \\
(-0.64)\end{array}$ & $\begin{array}{c}-0.0943 \\
(-0.64)\end{array}$ & & 0.793 & 0.0821 & 2.122 \\
\hline XI & $\begin{array}{l}1.2400 \\
(4.62)\end{array}$ & $\begin{array}{c}0.1115 \\
(2.80)\end{array}$ & $\begin{array}{c}-0.0213 \\
(-0.51)\end{array}$ & $\begin{array}{c}-0.1295 \\
(-4.30)\end{array}$ & $\begin{array}{c}-0.4459 \\
(-2.26)\end{array}$ & $\begin{array}{c}-0.0475 \\
(-0.71)\end{array}$ & & & $\begin{array}{c}-0.0632 \\
(-0.47)\end{array}$ & $\begin{array}{c}-0.0632 \\
(-0.47)\end{array}$ & & 0.790 & 0.089 & 2.106 \\
\hline $\begin{array}{l}\mathrm{C}=\text { Const } \\
\mathrm{E}=\text { Partic } \\
\mathrm{R}=(\text { Carte } \\
\mathrm{S}=(\text { Sect } \\
\left(\mathrm{r}_{\mathrm{a}}-\mathrm{r}_{\mathrm{p}}\right)=\mathrm{Ta}\end{array}$ & $\begin{array}{l}\text { nte } \\
\text { pación re } \\
\text { a vencid } \\
\text { r activa }\end{array}$ & $\begin{array}{l}\text { tiva del b } \\
\text { Crédito) } \\
\text { Tasa pasi }\end{array}$ & co en e & dito total & & $\begin{array}{l}r_{\pi}=\text { Rentabi } \\
\left(A_{1}\right)=\text { Secto } \\
\left(A_{2}\right)=\text { Secto } \\
\left(A_{3}\right)=\text { Secto } \\
\text { Los valores }\end{array}$ & $\begin{array}{l}\text { dad por } \\
\text { agrícola } \\
\text { agrícola } \\
\text { agrícola } \\
\text { a parént }\end{array}$ & $\begin{array}{l}\text { so captad } \\
\text { ector ind } \\
\text { ector serv } \\
\text { ec.Indus. } \\
\text { s son esta }\end{array}$ & $\begin{array}{l}\text { rial } \\
\text { ios } \\
\text { Sec. serv. } \\
\text { sticas t }\end{array}$ & $\begin{array}{l}\mathrm{P}=\mathrm{Pe} \\
\pi=\mathrm{In} \\
\mathrm{D}-\mathrm{W}= \\
\mathrm{e}=\mathrm{Er} \\
\mathrm{R}^{2}=\end{array}$ & $\begin{array}{l}\text { sonas fís } \\
\text { resos net } \\
\text { Durbin- } \\
\text { or estánd } \\
\text { oeficient }\end{array}$ & $\begin{array}{l}\text { s/Person } \\
\text { Capital } \\
\text { tson } \\
\text { de la reg } \\
\text { de deter }\end{array}$ & $\begin{array}{l}\text { morales } \\
\text { Reservas } \\
\text { sión } \\
\text { inación. }\end{array}$ & \\
\hline
\end{tabular}


3) El diferencial entre las tasas activa y pasiva; a medida que se reduce el margen de intermediación en que opera el banco, mayor es el monto promedio de sus créditos y menor es el número de acreditados del banco. Por ejemplo se puede citar a tres bancos medianos, los cuales al estar vinculados a fuertes grupos económicos reducen el margen de intermediación en que operan al tiempo que concentran sus créditos en las empresas del grupo al que pertenecen (cabe señalar que esto solamente se establece como una hipótesis). En el cuadro 8 se muestran las elasticidades del ICC respecto a las variables independientes y se esquematiza lo expresado en los párrafos anteriores.

Antes de abandonar este tema cabe hacer la aclaración que los análisis de regresión miden solamente el grado de relación funcional que existe entre variables, lo cual no necesariamente implica que exista una relación causa-efecto entre las mismas. Las hipótesis de causalidad que aquí se han expuesto son solamente eso, "hipótesis". Es evidente que aún resta mucho por elaborar sobre el tema.

\section{Consideraciones sobre la distribución regional de los servicios bancarios.}

La distribución geográfica de los servicios financieros es tal vez uno de los cuellos de botella en el desarrollo armónico de la actividad económica nacional que ha sido menos estudiado en la literatura financiera mexicana. Se reconoce en términos generales que el problema del financiamiento al desarrollo económico consiste en encontrar los medios para incrementar el ahorro y de esta manera alcanzar más altos niveles de inversión. La transferencia de recursos entre sectores de la población se puede realizar de diferentes maneras, por ejemplo, una inflación moderada puede inclusive ser benéfica para el desarrollo en tanto que facilita la transferencia de recursos de los sectores tradicionales hacia los sectores modernos de la economía. Claro que también se puede argumentar que esta transferencia fomenta la mala distribución del ingreso del sector laboral al empresarial en tanto los precios aumenten con mayor velocidad que los salarios. El sistema bancario del país, por su parte, facilita la transferencia de recursos del público con excedentes (ahorradores) hacia el público con faltantes (inversionistas), cuando dicho proceso se realiza se presenta además, en la mayoría de los casos, un traslado de los excedentes entre sectores de la actividad económica y entre regiones del país. 
Cuadro 8. Elasticidades del Indice de Concentración del Crédito Bancario

\begin{tabular}{|c|c|c|c|}
\hline Variable relevante & $\begin{array}{c}\text { Cambio porcentual } \\
\text { en el ICC debido a } \\
\text { un incremento de } \\
1.0 \% \text { en la variable } \\
\text { relevante } \underline{1} /\end{array}$ & $\begin{array}{c}\text { Bancos que } \\
\text { ejemplifican la } \\
\text { importancia de la } \\
\text { variable relevante }\end{array}$ & $\begin{array}{c}\text { ICC de los } \\
\text { bancos y lugar } \\
\text { que ocupan en la } \\
\text { concentración } 2 /\end{array}$ \\
\hline $\begin{array}{l}\text { Participación Relativa del Sector } \\
\text { Público en la Cartera de Crédito }\end{array}$ & $-0.6656^{\underline{3} /}$ & $\begin{array}{l}\text { Dos bancos } \\
\text { medianos } \\
\text { del Estado }\end{array}$ & $\begin{array}{r}10.14\left(1^{\circ}\right) \\
8.76\left(2^{\circ}\right)\end{array}$ \\
\hline Margen de Intermediación Financiera & $-0.6633^{3 /}$ & $\begin{array}{l}\text { Tres bancos } \\
\text { medianos con clara } \\
\text { vinculación } \\
\text { grupos } \\
\text { económicos }\end{array}$ & $\begin{array}{l}6.18\left(4^{\mathrm{o}}\right) \\
5.25\left(5^{\mathrm{o}}\right) \\
4.47\left(9^{\mathrm{o}}\right)\end{array}$ \\
\hline $\begin{array}{l}\text { Participación Relativa en los Recursos } \\
\text { Totales del } \quad \text { Sistema } \\
\text { Bancaria) }\end{array}$ & +0.0968 & $\begin{array}{l}\text { Los dos bancos más } \\
\text { grandes del sistema }\end{array}$ & $\begin{array}{l}5.19\left(6^{\circ}\right) \\
5.14\left(7^{\circ}\right)\end{array}$ \\
\hline
\end{tabular}

La conversión del sistema bancario mexicano en banca múltiple abre la posibilidad a los bancos pequeños a fusionarse fortaleciendo de esta manera su posición en el mercado, así el sistema se dirige hacia una nueva morfología, la cual se caracteriza por un número más reducido de grandes bancos. La concentración de los servicios financieros en unas cuantas instituciones de gran escala y de cobertura nacional propicia -como se señaló en los apartados anteriores- que el monto promedio de sus operaciones se eleve, este fenómeno lleva consigo la necesidad de ubicar su financiamiento en áreas donde la escala de la actividad económica es también mayor. Existe evidencia de que los bancos más grandes tienden a hacer una mejor distinción entre sus plazas de captación y sus plazas de financiamiento, quedando obviamente en este último grupo los centros de mayor desarrollo económico del país.

Si bien es cierto que la política bancaria de concentración de recursos financieros obedece a una lógica racional que consiste en asignar dichos recursos donde la demanda es mayor y muy probablemente el riesgo más bajo, también se debe admitir que al elevarse el monto de las operaciones activas al que desean trabajar los bancos y al elevarse también sus posibilidades de transferir recursos de una región a otra, se abre la posibilidad de dejar desprovisto del crédito necesario a un número -tal 
vez amplio- de proyectos relativamente pequeños en plazas de escaso desarrollo económico. Cabe apuntar que el hecho de que un proyecto económico sea pequeño o se localice en un área poco desarrollada no lo hace necesariamente poco rentable, ni mucho menos no recomendable socialmente hablando.

Debemos señalar que con la consolidación de la banca en grandes instituciones de servicios múltiples se plantea también una incógnita sobre el adecuado servicio financiero que habrán de recibir los usuarios del crédito ubicados en áreas de escaso desarrollo económico. La experiencia que se deriva del comportamiento de la banca privada y mixta durante los últimos treinta años puede resultar de gran utilidad sobre el particular, ya que su comportamiento a nivel de flujos regionales está dominada por las políticas que siguieron las dos instituciones bancarias más grandes del sistema, además estas instituciones son también la imagen hacia la cual se dirigen las instituciones que ahora surgen bajo el régimen de banca múltiple.

El objetivo de esta sección consiste precisamente en un análisis sobre el comportamiento de la banca privada y mixta en la concentración regional de los recursos. Dado que la información sobre flujos financieros en el interior del país es bastante limitada, se procedió a ajustar las cifras de tres fuentes distintas; 1) los datos contenidos en los cuadros de saldos bancarios importantes en la República Mexicana del Boletín Estadístico de la Comisión Nacional Bancaria, 2) las series históricas de captación y financiamiento contenidas en los Indicadores Económicos del Banco de México y por último, 3) la información reciente sobre la distribución por entidades federativas del crédito otorgado según ramas de actividad económica de la Serie Moneda y Banca del mismo instituto central. A fin de evitar repeticiones redundantes, las cifras y análisis que continúan se refieren solamente a la banca privada y mixta.

El cuadro 9 muestra la información básica integrada por regiones y para años selectos. La regionalización de la República se hizo en base a ocho zonas con características económicas, demográficas y sociales semejantes ${ }^{1 /}$. Todas las cifras del cuadro se expresan por la distinta densidad

$1 /$

Región I: Baja California Norte, Baja California Sur, Nayarit, Sonora y Sinaloa.

Región II: Coahuila, Chihuahua, Durango y Nuevo León.

Región III: Tamaulipas y Veracruz

Región IV: Aguascalientes, San Luis Potosí y Zacatecas.

Región V: Colima, Guanajuato, Jalisco y Michoacán.

Región VI: Morelos, Puebla, Querétaro, Tlaxcala e Hidalgo.

Región VII: Distrito Federal y México.

Región VIII: Guerrero, Oaxaca, Chiapas, Tabasco, Campeche, Yucatán y Quintana Roo. 
demográfica de las regiones en cuestión. En la parte superior del cuadro 9 se presentan las cifras de captación y financiamiento per cápita a nivel nacional y en la parte inferior las desviaciones de estos dos agregados (per cápita) para cada una de las regiones respecto de la captación media nacional en el año correspondiente. Por ejemplo, la captación por habitante en la región I fue $46.2 \%$ superior a la captación per cápita a nivel nacional en 1950, en tanto que el financiamiento de esa misma región fue sólo $32.6 \%$ superior a la CAPTACIÓN per cápita nacional de ese mismo año. Es decir, todas las cifras se presentan en relación a la captación del año correspondiente y por habitante.

En promedio, la banca privada y mista, dispuso de 68 centavos para financiamiento por cada peso que captó por habitante entre 1950 y 1978, destinado a reservas los 32 centavos restantes. Además se aprecia que la tendencia de las reservas bancarias ha sido creciente durante el mismo período; la captación real per cápita creció a un promedio anual de $15.9 \%$ en tanto que el financiamiento real per cápita lo hizo a un 13.0\%. Es decir, los recursos disponibles a los bancos de lo captado- para financiar a las empresas y los particulares se redujeron a una tasa anual de casi $3.0 \%$. Esto se debe en gran medida a que el banco central elevó los niveles del encaje legal, por cada peso captado por la banca en 1950, ésta disponía de 69 centavos para financiar directamente a la actividad económica, en tanto que en 1978 por cada peso captado por estas instituciones, solamente dispusieron de 57 centavos para atender a la demanda por crédito de sus clientes.

Algunas regiones presentan cambios con tendencia definida entre 1950 y 1978 dentro de la estructura total financiera. Por ejemplo, durante el período la captación per cápita en la región IV prácticamente se duplicó, así como el financiamiento per cápita otorgado a la región VIII se cuadruplicó, ambas en relación ala media nacional. Sin embargo, estos cambios no han sido lo suficientemente significativos como para modificar la estructura regional. En primer término, la captación por habitante en las regiones I, II y VII es superior a la media nacional durante todo el período que contempla. Las regiones I y II, que representan el norte de la República Mexicana, presentan depósitos per cápita por encima de la media nacional para todos los años. Por su parte, la captación anual por habitante en el Distrito Federal y Estado de México fue en promedio 2.4 veces superior a la media nacional en los últimos 30 años.

Por lo que respecta al sureste del país (región VIII), los depósitos, aunque crecientes, han sido siempre los más bajos de la República, ya antes señalábamos que estos pasaron de representar 0.201 de la media per cápita nacional en 1950 a 0.519 de la misma en 1978. 
Cuadro 9

Distribución Regional Per cápita de la Captación y el

Financiamiento de la Banca Privada y Mixta

(Moneda nacional y moneda extranjera)

\begin{tabular}{|c|c|c|c|c|c|c|c|c|c|c|c|c|c|c|c|}
\hline & \multicolumn{2}{|c|}{1950} & \multicolumn{2}{|c|}{1955} & \multicolumn{2}{|c|}{1960} & \multicolumn{2}{|c|}{1965} & \multicolumn{2}{|c|}{1970} & \multicolumn{2}{|c|}{1975} & \multicolumn{2}{|c|}{1978} \\
\hline & & Captado & Financiado & Captado & Financiado & Captado & $\begin{array}{l}\text { Financiad } \\
\mathrm{o}\end{array}$ & Captado & $\begin{array}{l}\text { Financiad } \\
\mathrm{o}\end{array}$ & Captado & $\begin{array}{l}\text { Financiad } \\
0\end{array}$ & Captado & Financiado & Captado & Financiado \\
\hline $\begin{array}{l}\text { Per cápit } \\
\$)\end{array}$ & nacional (miles de & 195.3 & 135.7 & 326.2 & 244.1 & 596.6 & 460.9 & 1233.0 & 810.4 & $\begin{array}{c}2 \\
506.4\end{array}$ & 1807.5 & $\begin{array}{c}4 \\
675.8\end{array}$ & 2823.1 & 8367.7 & 4777.7 \\
\hline \multirow{2}{*}{\multicolumn{2}{|c|}{$\begin{array}{l}\text { Distribución de peso per } \\
\text { cápita captado a nivel } \\
\text { nacional }\end{array}$}} & 1.00 & 0.69 & 1.00 & 0.75 & 1.00 & 0.77 & 1.00 & 0.66 & 1.00 & 0.72 & 1.00 & 0.60 & 1.00 & 0.57 \\
\hline & & \multicolumn{12}{|c|}{ DESVIACIONES RESPECTO DE LA MEDIA NACIONAL PERCAPITA } & & \\
\hline Región & I & 1.462 & 1.326 & 1.978 & 1.345 & 1.615 & 0.912 & 1.682 & 0.738 & 1.695 & 0.632 & 1.859 & 0.602 & 1.577 & 0.736 \\
\hline Región & II & 1.441 & 1.173 & 1.479 & 1.408 & 1.281 & 1.448 & 1.259 & 1.195 & 1.265 & 1.288 & 1.138 & 1.050 & 1.162 & 0.715 \\
\hline Región & III & 0.738 & 0.465 & 0.718 & 0.413 & 0.778 & 0.376 & 0.819 & 0.344 & 0.779 & 0.281 & 0.805 & 0.259 & 0.812 & 0.329 \\
\hline Región & IV & 0.317 & 0.180 & 0.297 & 0.139 & 0.397 & 0.161 & 0.412 & 0.143 & 0.510 & 0.172 & 0.529 & 0.188 & 0.600 & 0.234 \\
\hline Región & V & 0.399 & 0.267 & 0.509 & 0.253 & 0.502 & 0.242 & 0.663 & 0.278 & 0.795 & 0.319 & 0.848 & 0.325 & 0.875 & 0.380 \\
\hline Región & VI & 0.329 & 0.239 & 0.298 & 0.200 & 0.377 & 0.183 & 0.417 & 0.157 & 0.458 & 0.159 & 0.474 & 0.133 & 0.511 & 0.192 \\
\hline Región & VII & 3.109 & 1.796 & 2.515 & 2.121 & 2.740 & 2.715 & 2.409 & 2.263 & 2.114 & 2.788 & 1.892 & 2.138 & 1.941 & 1.803 \\
\hline \multirow[t]{2}{*}{ Región } & VIII & 0.201 & 0.112 & 0.203 & 0.106 & 0.306 & 0.140 & 0.336 & 0.141 & 0.379 & 0.128 & 0.453 & 0.134 & 0.519 & 0.176 \\
\hline & & & .642 & & .767 & & .911 & & .746 & & .920 & & .693 & & .544 \\
\hline \multicolumn{2}{|c|}{ Desviación estándar } & .988 & & .880 & & .846 & & .736 & & .633 & & .587 & & .524 & \\
\hline
\end{tabular}


Si bien es cierto que la estructura en la distribución regional de la captación per cápita se mantiene a través de los años presentados en el cuadro 9, también hay que notar que la disparidad entre las regiones se ha reducido, como se puede observar, la dispersión de los datos entre las regiones es cada vez menor. La desviación estándar de la distribución regional de la captación decrece sistemáticamente de 0.988 en 1950 a 0.524 en 1978. Es decir, el excedente de recursos para el ahorro por habitante en las diferentes regiones del país tiende hacia una mayor uniformidad.

Por su parte, la estructura en la distribución regional del financiamiento de la banca privada y mixta es prácticamente la misma a la observada para la captación. Las regiones I, II y VII son las más beneficiadas por el crédito privado, en tanto que las regiones VI y VIII reciben sistemáticamente una menor proporción del financiamiento. Sin embargo, la tendencia decreciente en la dispersión regional de la captación-per cápita no se observa en el caso del financiamiento; por el contrario, entre $1950 \mathrm{y}$ 1970, las diferencias en el financiamiento por habitante entre las regiones tendieron a agrandarse, pasando la desviación estándar de la distribución de 0.642 a 0.920 (ver parte inferior del cuadro 9). Cabe notar que entre 1970 y 1978, la dispersión del financiamiento per cápita entre las regiones se reduce drásticamente; la desviación estándar bajó a 0.544 en la última fecha.

Lo anterior es un hallazgo importante que puede tener varias interpretaciones. Por ejemplo, si aceptamos que la captación de recursos del público no es discriminatorio, en tanto que el financiamiento obedece a criterios rigurosos de eficiencia, rentabilidad y recuperabilidad, podremos aseverar que la banca privada y mixta realiza -al canalizar los recursos de ahorradores a inversionitasun proceso de intermediación financiera no favorable al desarrollo armónico del país ya que concentra recursos en las regiones de alta concentración de la riqueza. Es decir, los recursos que son generados en regiones de escaso desarrollo económico y que son depositados en los bancos, son utilizados para financiar proyectos en regiones donde la infraestructura económica es mayor. Las cifras del cuadro 9 indican que hubo una transferencia de recursos financieros de las regiones poco desarrolladas a las regiones más desarrolladas del país y que dicho proceso fue particularmente intenso entre 1950 y 1970 , tendiendo a atenuarse durante la década de los setentas.

No obstante la raquítica que es la información estadística histórica sobre concentración regional de los servicios bancarios, se trató de cuantificar de alguna manera la transferencia de recursos financieros entre regiones que realiza la banca privada y mixta. El cuadro 10 muestra la distribución regional per cápita de un peso captado por la banca en promedio entre 1959 y 1978. 
Por cada peso captado-per cápita en la República Mexicana, los habitantes del D.F. y Estado de México (región VII) aportan casi un tercio, el norte del país (regiones I y II) aportan 37.3 centavos y las cinco regiones restantes contribuyen con la diferencia sin alcanzar cada una de ellas una aportación superior a los 10 centavos. 32 centavos son destinados a reservas y los 68 centavos restantes son distribuidos por la banca en forma de financiamiento. En la distribución regional del financiamiento de la región VII (D.F. y Estado de México) recibe la mayor proporción; casi 28 centavos del peso captado-per cápita a nivel nacional, por tanto su aporte a reservas no llega a los dos centavos. En el extremo opuesto, la región VIII (sureste del país) recibe en forma de financiamiento privado 1.7 centavos por habitante, no obstante que su aportación a la captación-per cápita nacional fue de 4.3 centavos de cada peso. Estos elementos indican que la aportación a reservas bancarias de los habitantes del sureste del país es 37.0\% superior a la correspondiente a la de los habitantes del Distrito Federal y Estado de México, no obstante que los primeros solamente aportan a la captación 4.3 centavos por cada 29.8 centavos de los segundos. Las disparidades entre la captación y el financiamiento por regiones durante el período han significado una distribución regional regresiva de los recursos financieros. Como se puede apreciar en el cuadro 10, alrededor del 50\% de los depósitos bancarios de las regiones I, III, V, VI y VIII abandonan su ámbito geográfico. Las regiones II y VII, en contraste, reciben en forma de financiamiento más de 90\% de sus depósitos bancarios. Evidentemente, este análisis no profundiza sobre el destino que el sector público ha dado a los depósitos en reservas (Encaje) de la banca privada y mixta.

\section{Cuadro 10}

Distribución regional de un peso captado per cápita por la banca privada y mixta (Promedio de los años: 1950, 55, 60, 65, 70, 75 y 78)

\begin{tabular}{lcccc}
\hline Región & $\begin{array}{c}\text { Captación } \\
(1)\end{array}$ & $\begin{array}{c}\text { Financiamiento } \\
(2)\end{array}$ & $\begin{array}{c}\text { Aportación a } \\
\text { reservas } \\
(1)-(2)=(3)\end{array}$ & $\begin{array}{c}\text { Porcentaje de } \\
\text { reservas a } \\
\text { captación }\end{array}$ \\
\hline & & & & \\
I & 0.212 & 0.112 & 0.100 & 47.16 \\
II & 0.161 & 0.148 & 0.013 & 8.07 \\
III & 0.097 & 0.044 & 0.053 & 54.63 \\
IV & 0.055 & 0.022 & 0.033 & 60.00 \\
V & 0.082 & 0.037 & 0.045 & 54.87 \\
VI & 0.051 & 0.022 & 0.029 & 56.86 \\
VII & 0.298 & 0.279 & 0.019 & 6.37 \\
VIII & 0.043 & 0.017 & 0.026 & 60.46 \\
Reservas & & 0.320 & & \\
T o t a 1 & 1.00 & 1.00 & 0.318 & \\
& & & & \\
\hline
\end{tabular}


Dada la política de fomento industrial de los gobiernos de la posguerra, podemos aseverar que no existe evidencia de que los recursos provenientes de reservas bancarias hayan sido utilizados por el sector público en dirección opuesta al flujo financiero regional realizado por la banca privada y mixta. Podríamos suponer en el extremo que dichos recursos financieros son asignados geográficamente en forma equiproporcional a la población de cada región, es decir, la acción financiera de intermediación de esos recursos sería neutral en el fomento geográfico de la actividad económica. Aun en ese extremo, los desequilibrios originados por la banca privada y mixta en la distribución regional de los recursos financieros no habrían quedado resueltos; la región VII habría recibido recursos financieros 18.0\% superiores a su aportación per cápita en tanto que las regiones I, III y IV (únicas deficitarias bajo este supuesto) habrían recibido solamente el $70.0 \%$ de los recursos captados por la banca privada en su ámbito geográfico. En todo caso, resulta difícil aceptar el supuesto de la neutralidad geográfica de las reservas bancarias, especialmente si contemplamos la distribución por estados del gasto público. Es claro que la política de polos de desarrollo seguida por el gobierno durante la posguerra ha coadyuvado en forma relevante el desequilibrio geográfico de la actividad económica y a la concentración regional del ingreso nacional.

Para terminar con el análisis de esta sección, en el cuadro 11 se muestran los excedentes o faltantes financieros de cada región una vez que la banca ha cubierto los requerimientos de reservas correspondientes. Este cuadro se elaboró al igual que el anterior, partiendo de un peso captado por habitante a nivel nacional y en promedio durante el período 1950-1978.

\section{Cuadro 11}

Transferencia Regional de Recursos Financieros de la Banca Privada y Mixta por cada Peso Captado por Habitante En La República Mexicana

\begin{tabular}{rcccc}
\hline Región & $\begin{array}{c}\text { Aportación teórica } \\
\text { a reservas }(32.0 \% \\
\text { de la captación) } \\
(1)\end{array}$ & $\begin{array}{c}\text { Aportación real } \\
\text { a reservas }\end{array}$ & $\begin{array}{c}\text { Transferencia de } \\
\text { Recursos } \\
\text { Financieros } \\
(1)-(2)=(3)\end{array}$ & $\begin{array}{c}\text { Porcentaje de la } \\
\text { transferencia a } \\
\text { la captación }\end{array}$ \\
\hline I & 0.068 & $(2)$ & -0.032 & $-(15.09)$ \\
II & 0.051 & 0.100 & +0.038 & $+(23.60)$ \\
III & 0.031 & 0.013 & -0.022 & $-(22.68)$ \\
IV & 0.018 & 0.053 & -0.015 & $-(27.27)$ \\
V & 0.026 & 0.033 & -0.019 & $-(23.17)$ \\
VI & 0.016 & 0.045 & -0.013 & $-(25.49)$ \\
VII & 0.096 & 0.029 & +0.077 & $+(25.83)$ \\
VIII & $\underline{0.014}$ & 0.019 & -0.012 & $-(27.90)$ \\
& 0.320 & 0.026 & 0.000 & \\
\hline
\end{tabular}


Como se puede apreciar el proceso de redistribución de recursos financieros va de los estados que comprenden las regiones I, III, IV, V, VI y VIII a los estados de las regiones II y VII. Los estados de la República que más padecen una fuga de recursos financieros a través de la banca privada y mixta son los que se encuentran localizados en las regiones VIII y IV, que a su vez son más pobres del país. El sureste aporta 4.3 centavos de cada peso captado en la República por las instituciones privadas, éstas revierten a la región solamente 1.7 centavos, destinan teóricamente a sus reservas 1.4 centavos y transfieren a otra parte de la República 1.2 centavos. Esto es, el $27.9 \%$ de los recursos financieros del sureste del país depositados en los bancos privados es utilizado por estas instituciones para financiar el consumo ola inversión en otra región, sin olvidar además que el 32.0\% de esos mismos depósitos se envían a reservas, cuyo destino final se desconoce.

En el extremo opuesto se encuentran el Distrito Federal y el Estado de México (región VII), cuyo aporte es de 29.8 centavos de cada peso captado por los bancos privados a nivel nacional, de esta participación destinan a reservas teóricas 9.6 centavos. Estos estados reciben del resto de la República 7.7 centavos para financiar su consumo e inversión a través de la transferencia de recursos que realizan las instituciones privadas, en consecuencia el financiamiento total por habitante en el Distrito Federal y el Estado de México de la banca privada asciende a 27.9 centavos por cada peso captado por habitante a nivel nacional. Es decir, el 93.6\% de la captación-per cápita privada en la región VII se revierte en forma de financiamiento privado. La aportación a reservas se reduce a $6.4 \%$ del monto captado y resta por conocer la proporción que recibe de financiamiento oficial proveniente de las reservas bancarias.

La lógica de la descripción anterior se puede repetir para cualquiera de las regiones en que se dividió a la República Mexicana, haciendo uso de los cuadros 10 y 11.

Lo antes expuesto nos permite apreciar por una parte la estructura regional de los servicios bancarios privados, los cuales están íntimamente ligados a los polos de desarrollo de la actividad económica. Por otra parte y más importante, se distingue que entre 1950 y 1978 tuvo lugar un proceso redistributivo de recursos financieros a favor de los estados con población predominantemente urbana y de actividad predominantemente industrial y de servicios. La intermediación financiera realizada por la banca privada y mixta ha contribuido en forma relevante a la fuga de recursos financieros de estados predominantemente rurales y dedicados a actividades primarias a favor de los estados donde el rendimiento de la inversión es más elevado. Indudablemente, la infraestructura de que disponen las regiones II y VII de la República Mexicana son un atractivo a los recursos financieros privados, ya que tienden a elevar considerablemente el rendimiento de la inversión privada. Asimismo, los proyectos 
industriales ofrecen garantías tangibles que mejor se adaptan a los criterios de análisis de la rentabilidad económica.

\section{Instituciones Financieras no Bancarias.}

Dada la importancia relativa que tiene el sistema bancario como componente del sector financiero, la política monetaria de los últimos treinta años se ha diseñado prácticamente en función de sus instituciones. No es sino hasta últimas fechas que se ha prestado mayor atención al comportamiento de los agentes financieros no bancarios; en gran medida esta nueva preocupación ha surgido como resultado de los cambios espectaculares que ocurrieron en el mercado bursátil después de 1976 y a la necesidad de crear un verdadero mercado financiero de largo plazo, proceso al que no se ha podido comprometer a la supuesta banca de inversión. De la estructura actual de los agentes financieros no bancarios dependen en gran medida las posibilidades de impulsar su desarrollo como un mercado financiero importante e independiente. En esta sección habremos de analizar dos aspectos importantes relacionados con la estructura de los intermediarios no bancarios; se presenta un esquema sucinto de la concentración de recursos en el sector financiero no bancario y del grado de dependencia que éste acusa respecto a las instituciones bancarias más importantes del país.

A. Mercado de valores. Un papel clave dentro de las operaciones bursátiles es el que juegan las casas de bolsa ya que es a través de ellas como se realiza la intermediación financiera de este mercado. Las posibilidades de las empresas para emitir títulos de deuda dependen primordialmente de su solvencia económica y estado general de sus finanzas, sin embargo, una vez que han sido autorizadas e inscritas en la Comisión Nacional de Valores para emitir dichos títulos de deuda, un segundo paso consiste en contar con la casa de bolsa dispuesta a solventar la responsabilidad de la colocación primaria de los valores emitidos. De esta manera el poder de las casas de bolsa para influir en la actividad financiera del mercado de valores es indiscutible. Además, hay que tomar en cuenta que las casas de bolsa influyen también sobre las decisiones del público adquiriente (sus clientes), al cual brindan asesoría bursátil.

Cuando el número de corredores de bolsa es muy elevado, las posibilidades que estos tienen para afectar el valor y volumen de los títulos que se operan en el mercado se reduce. Las condiciones de competencia entre las casas de bolsa garantizan que el mercado emita mejores señales sobre las condiciones generales de la economía, el rendimiento de capital de las empresas con colocaciones bursátiles, la demanda por liquidez y las expectativas del público ahorrador e inversionista. 
Obviamente, dicha virtud de un mercado de valores para emitir señales adecuadas se demerita en la medida en que se ejerce control sobre las emisiones y la composición de la cartera de valores de los ahorradores que concurren a éste.

Así, la presencia de unas cuantas casas de bolsa conducen necesariamente a una distorsión de los objetivos básicos de un mercado bursátil; la Bolsa Mexicana de Valores adolece de esta severa restricción. Dos casas de bolsa manejan aproximadamente el $37 \%$ de las operaciones con acciones realizadas en el mercado, si sumamos a éstas dos casas más la participación se eleva a más de la mitad de todas las operaciones correspondientes, es decir, menos del 10\% de los agentes bursátiles ejercen control sobre poco más del $50 \%$ de las operaciones con acciones realizadas. En el cuadro 12 se muestran las participaciones en el mercado de los diferentes agentes bursátiles en 1978 y 1979.

La concentración de las operaciones bursátiles en unos cuantos agentes de bolsa es una seria limitación a las condiciones competitivas del mercado, sin embargo, los impedimentos a que el mercado se desenvuelva libremente van más allá. La participación de las casas de bolsa bancarias es sumamente relevante dentro del total de operaciones realizadas con acciones; superior al $35 \%$ del total (ver cuadro 12). Por tanto se puede esperar del papel que juega la bolsa de valores como competidor del sistema bancario cuando más de un tercio de las operaciones realizadas en el primero están controladas por casas filiales de las principales instituciones del segundo.

Así también, la influencia de la banca en la estructura bursátil es determinante a través de las sociedades de inversión. En el país operan actualmente cuatro sociedades de inversión y todas ellas dependen de grupos bancarios. El estudio "La Bolsa de Valores: Evolución Reciente y Perspectivas", elaborado por la $\mathrm{SHCP}^{1 /}$ señala que las instituciones bancarias se han servido de las sociedades de inversión como instrumento auxiliar de financiamiento de su grupo, ya que concentran una gran proporción de su cartera en inversiones en títulos de compañías cuyo accionista principal es el propio banco. Al caso se cita el ejemplo de una sociedad de inversión en la que en la que en 1978 el 53.4\% de las inversiones se realizaron en valores del mismo "grupo", cifra que se eleva a $73 \%$ al incluir los valores en cartera pertenecientes a otros grupos bancarios. Cabe destacar que solamente en títulos bancarios esta sociedad de inversión mantuvo en su cartera el $23.33 \%$.

\footnotetext{
1 R. Abarca y R. Rodríguez. "La Bolsa de Valores: Evolución reciente y perspectivas”. Dirección General de Planeación Hacendaria, Dirección de Investigación Económica, Secretaría de Hacienda y Crédito Público. Documento de Trabajo Num. 3. Mayo-Junio de 1980.
} 
El mismo documento hace mención de un aspecto importante en lo que se refiere a concentración de recursos operados en el mercado de valores y es el que se refiere a las compañías registradas en bolsa y en cuya lista de accionistas principales aparece un banco. En el cuadro 13 aparece un listado de las empresas ligadas a los bancos más importantes del país, las empresas no sólo constituyen una porción muy importante del mercado bursátil, sino además una fracción muy relevante del aparato productivo del país.

\section{Cuadro 12}

Operaciones con Acciones Realizadas en la Bolsa de Valores

\begin{tabular}{|c|c|c|c|c|}
\hline \multirow[b]{2}{*}{ A g e n t e } & \multicolumn{2}{|c|}{1978} & \multicolumn{2}{|c|}{1979} \\
\hline & Importe & $\%$ & Importe & $\%$ \\
\hline Casa de Bolsa Banamex & 32866.7 & 21.35 & 40178.7 & 21.42 \\
\hline Acciones y Valores de México & 24232.5 & 13.76 & 28839.0 & 15.37 \\
\hline Operadora de Bolsa & 10437.9 & 6.78 & 14013.8 & 7.47 \\
\hline Probursa, S.A. & 10769.1 & 6.99 & 12910.6 & 6.88 \\
\hline Otras casas de bolsa bancarias (7) & 24293.5 & 15.78 & 18893.9 & 15.41 \\
\hline Otras casas de bolsa no bancarias (17) & 48942.2 & 31.78 & 59907.1 & 31.94 \\
\hline Otros agentes (13) & 2407.1 & 1.58 & 2825.4 & 1.51 \\
\hline T O T A L & 153989.0 & 100.0 & 187568.5 & 100.0 \\
\hline
\end{tabular}

Fuente: Roberto Rodríguez "Algunos aspectos de la Bolsa de Valores”. SCHP. R. Abarca y R. Rodríguez "La Bolsa de Valores: Evolución reciente y perspectivas". SHCP.

La información disponible no permite cuantificar el monto del crédito bancario concedido a las empresas del "grupo", elemento que nos habría permitido aproximarnos a evaluar la concentración del crédito financiero (bancario y bursátil) en estas grandes empresas filiales o asociadas a un banco. No obstante tal limitación al considerar el listado que aparece en el cuadro 13 y tomar en cuenta que entre las variables que más influyen en la concentración del crédito bancario está la escala de operación del banco y el sacrificio que éste toma sobre su margen de intermediación, podemos intuir que la concentración de recursos financieros en grupos económicos es considerable. 
Cuadro 13

Empresas de la Bolsa de Valores en las que un Banco es uno de sus Principales Accionistas

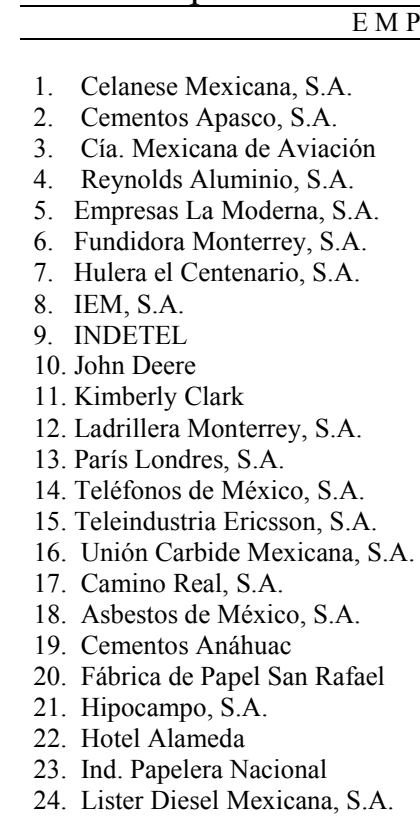

25. Aceros Esmaltados, S.A.

26. Sosa Texcoco, S.A.

27. Vehículos Automotores Mex.

$\begin{array}{ll} & \text { A C T I V I D A D } \\ \text { BANAMEX } & \text { (Química) } \\ & \text { (Cemento) } \\ & \text { (Servicios) } \\ & \text { (Metalúrgica) } \\ & \text { (Tabaco) } \\ & \text { (Metalúrgica) } \\ & \text { (Hule) } \\ & \text { (Electrónica) } \\ & \text { (Electrónica) } \\ & \text { (Vehículos, Maquinaria) } \\ & \text { (Celulosa y Papel) } \\ & \text { (Mat. de Construcción) } \\ & \text { (Comercio) } \\ & \text { (Teléfonos) } \\ & \text { (Eléctrico-Electrónica) } \\ & \text { (Química) } \\ & \text { (Hoteles) } \\ & \text { (Mat. de Construcción) } \\ \text { (Cementos) } \\ \text { (Celulosa y Papel) } \\ \text { (Bienes Raíses, Hoteles) } \\ \text { (Hoteles) } \\ \text { (Editorial) } \\ \text { (Autopartes) } \\ \end{array}$

BANCA SOMEX

(Metalúrgica)

(Química)

(Vehículos)

28. Anderson Clayton

29. El Puerto de Liverpool, S.A.

30. Frisco, S.A.

31. General Electric, S.A.

32. Pigmentos y Productos Químicos

33. Cementos Anáhuac

34. Progresa, S.A. de C.V

35. Productos Mexalit, S.A.

BANCOMER

(Alimentos)
(Comercio)
(Eléctrica)
(Eléctrica)
(Química)
(Cemento)
(Editorial)
(Mat. de Construcción)

36. El Puerto de Liverpool, S.A.

37. A. C. Mexicana

38. Fundidora Tepeyac

39. Ladrillera Monterrey, S.A.

40. Fomento de Industria y Descuento, S.A.

Mat. de Construccion)

SERFIN

41. Central de Malta, S.A.

42. Cervecería Moctezuma, S.A.

43. Sanborns Mexicana, S.A.

BANCO MEXICANO

\section{(Comercio) \\ (Maquinaria) \\ (Acero) \\ (Materiales) \\ (Vidrio)}

\section{(Alimentos) \\ (Cervecera) \\ (Comercio)}

\section{NACIONAL FINANCIERA}

(Acero)
(Tabacalera)
(Celulosa y Papel)
(Minería)
(Acero)
(Eléctrica)
(Metalúrgica)
(Cemento)

Otros nueve bancos son los principales accionistas de 16 compañías en la Bolsa de Valores.
44. Altos Hornos de México, S.A.

45. Cigarros La Tabacalera Mexicana

46. Cía. Industrial San Cristobal

47. Cía. Minera de Cananea

48. Fundidora Monterrey, S.A.

49. Grupo Condumex, S.A.

50. Tubos de Acero de México, S.A.

51. Cementos Guadalajara, S.A.

Fuente: Anuario Financiero y Bursátil 1978. B.M.V. 
En conclusión, los elementos que aparecen en este apartado ponen de manifiesto que el mercado de valores acusa un alto grado de concentración y dependencia respecto al sistema bancario. Por tanto, no resulta infundado aseverar que el futuro del marcado bursátil como un competidor verdadero e independiente en la captación de recursos financieros es bastante cuestionable.

B. Compañías de seguros. Este ramo de la actividad financiera estuvo dominada por compañías extranjeras hasta 1935. El proceso de mexicanización que se inició con los cambios en la ley de 1926 amplió las posibilidades a unas cuantas compañías mexicanas para consolidar una posición en el mercado. Junto a la consolidación de solamente tres compañías como las más importantes del mercado en 1960, se aprecia también un estancamiento en la profundización de estos servicios financieros en la actividad económica del país; el PIB real creció a una tasa media anual de $6.2 \%$ entre 1950 y 1980 en tanto que el crecimiento real de las primas cobradas durante el mismo lapso arroja una tasa media anual de $6.6 \%$, es decir, la penetración de la industria aseguradora en el sector real fue prácticamente insignificante durante los últimos treinta años.

Actualmente, la concentración de recursos en el sector se ha elevado al punto que solamente seis compañías manejan aproximadamente el 53\% de los activos totales, esto significa que el 12.5\% de las aseguradoras contabilizan poco más de la mitad de los recursos de esta rama de la actividad financiera. Cabe mencionar además que existe una brecha considerable entre la escala de operación de las seis compañías más grandes y el resto, ya que la séptima en importancia por monto de recursos es casi 4.5 veces más pequeña que laque le antecede. En cuadro 14 se reportan los activos totales de las compañías de seguros más importantes en 1979, así como su participación relativa dentro de los recursos del sistema asegurador. 
Cuadro 14.

Distribución de los Recursos del Sistema Asegurador (1979

Institución

Millones

de pesos

$\%$

Cías. Aseguradoras más importantes

$\begin{array}{rr}25626.4 & 53.0 \\ 5672.4 & 11.7 \\ 4711.5 & 9.7 \\ 4468.0 & 9.2 \\ 4061.2 & 8.4 \\ 3461.6 & 7.2 \\ 3251.7 & 6.7 \\ 22729.6 & 47.0\end{array}$

Seguros América Banamex, S.A.

10

Seguros Monterrey Serfín, S.A.

9.7

Seguros La Comercial, S.A.

Seguros Bancomer, S.A.

Seguros Provincial, S.A.

9.2

Seguros La Nacional, S.A.

8.4

7.2

Resto del Sector Asegurador

22729.6

47.0

Total

48356.0

100.0

Cuadro 15. Compañías de Seguros Bancarios

Activos Totales

(Millones de Pesos)

\begin{tabular}{|c|c|c|c|c|}
\hline & \multicolumn{2}{|c|}{1978} & \multicolumn{2}{|c|}{1979} \\
\hline & Abs. & Rel. & Abs. & Rel. \\
\hline BANAMEX & & & & \\
\hline Seguros América-Banamex, S.A. & 4061.5 & 17.8 & 5672.4 & 19.0 \\
\hline Seguros Del Pacífico, S.A. & 105.7 & .46 & 150.7 & .50 \\
\hline $\begin{array}{l}\text { Seguros La Territorial, S.A. } \\
\text { COMERMEX }\end{array}$ & 323.2 & 1.41 & 444.9 & 1.49 \\
\hline Seguros La Comercial, S.A. & 3332.2 & 14.6 & 4468.0 & 15.0 \\
\hline Seguros La Comercial de Chihuahua, S.A. & 156.0 & .68 & 203.7 & .68 \\
\hline Seguros La Comercial de Occidente & 132.7 & .58 & 146.2 & .49 \\
\hline Seguros La Comercial de Puebla & 20.2 & .08 & 26.8 & .08 \\
\hline Seguros La Comercial del Noreste & 65.3 & .28 & 68.3 & .22 \\
\hline Seguros La Comercial del Norte & 149.5 & .65 & 188.9 & .63 \\
\hline $\begin{array}{r}\text { La Latinoamericana, S.A. } \\
\text { CREMI }\end{array}$ & 594.0 & 2.60 & 656.3 & 2.20 \\
\hline La Nacional, S.A. & 2559.8 & 11.2 & 3251.7 & 10.9 \\
\hline $\begin{array}{r}\text { Seguros Provincial, S.A. } \\
\text { SERFIN }\end{array}$ & 2574.6 & 11.3 & 3461.6 & 11.6 \\
\hline $\begin{array}{c}\text { Seguros Monterrey-Serfín, S.A. } \\
\text { BANCOMER }\end{array}$ & 3854.0 & 16.9 & 4711.5 & 15.8 \\
\hline $\begin{array}{l}\text { Seguros Bancomer, S.A. } \\
\text { OTRAS BANCARIAS }\end{array}$ & 3111.3 & 13.6 & 4061.2 & 13.6 \\
\hline Aseguradora Banpaís, S.A. & 115.6 & .5 & 185.1 & .62 \\
\hline La Atlántida, Seguros Generales, S.A. & 104.5 & .45 & 140.0 & .47 \\
\hline Seguros Atlas, S.A. & 387.1 & 1.7 & 491.6 & 1.6 \\
\hline Seguros del Atlántico, S.A. & 323.3 & 1.42 & 465.5 & 1.5 \\
\hline Seguros Equitativa BCH, S.A. & 214.9 & .94 & 234.9 & .78 \\
\hline Seguros Independencia Bancreser, S.A. & 580.8 & 2.55 & 740.8 & 2.48 \\
\hline TOTAL ASEGURADORAS BANCARIAS & 22765.9 & 100.0 & 29770.0 & 100.0 \\
\hline
\end{tabular}


La falta de condiciones de competencia en el mercado de seguros está relacionado con la dependencia de este sector respecto del bancario; las aseguradoras dependientes de un banco reportaron recursos por 29769.9 millones de pesos en 1979, que representan el 61.6\% de los recursos totales. Dos instituciones bancarias (Banamex y Comermex) mantienen vínculos estrechos con nueve compañías de seguros, las cuales sumaron en 1979 el $40.3 \%$ de los activos totales. En el cuadro 15 se listan las compañías de seguros bancarias. Cabe aclarar que el grado de dependencia entre las compañías de seguros y los bancos varía en cada caso.

C. Compañías de fianzas. Podemos aseverar que en general estas instituciones atraviesan por el mismo tipo de problemas por los que atraviesa la industria aseguradora. El sector se compone de catorce instituciones (1979); número que en sí ya representa una limitación al desarrollo de condiciones competitivas en el mercado afianzador. Del total de afianzadoras, la mitad son filiales de alguna institución bancaria, esto -como ya antes hemos reiterado- deteriora las condiciones de competencia que teóricamente debieran prevalecer en el mercado financiero entre los diferentes agentes que a él concurren. Asimismo, de las 14 compañías de fianzas tres de ellas controlan el $40 \%$ de los recursos totales. En el cuadro 16 se muestran los activos totales de las compañías de fianzas en 1978 y 1979, clasificadas en bancarias e independientes.

En el inciso A de esta sección pusimos en relieve la influencia que ejercen las instituciones bancarias en el mercado bursátil a través de sus casas de bolsa, sociedades de inversión y empresas emisoras de títulos de deuda y de las que los bancos son principalmente accionistas. Del mismo modo también señalamos en el inciso B, que las compañías de seguros vinculadas a algún banco controlan el $61.5 \%$ de los recursos totales del sistema asegurador (ver cuadros 14 y 15). Por lo que se refiere a las compañías de fianzas encontramos una situación similar; siete establecimientos afiliados a algún banco disponen del 52.9\% de los recursos del sector (ver cuadro 16). Al reflexionar sobre todos estos elementos en forma conjunta, nos encontramos con que el panorama del mercado bursátil como agente financiero independiente es aún más estrecho; las compañías de fianzas y las compañías de seguros constituyen la fracción más importante de los adquirentes institucionales de la Bolsa de Valores, consecuentemente su dependencia a establecimientos bancarios muy probablemente influye sus preferencias en la compra de valores; es factible suponer que sus operaciones bursátiles se canalicen a través de la casa de bolsa correspondiente y estén orientadas hacia la adquisición de las acciones y títulos de deuda de las empresas del grupo. La validez de esta hipótesis no se pudo corroborar ya que 
no es posible obtener información sobre el contenido de las carteras bursátiles de las compañías de fianzas y de seguros, sin embargo, cabe reconocer que es una hipótesis bastante plausible.

D. Almacenes generales de depósito. Las actividades de este tipo de organizaciones auxiliares de crédito se encuentran dominadas por la participación estatal. Al finalizar 1979 existían en el país 29 establecimientos de esta naturaleza con activos por 2032 millones de pesos; de este total solamente Almacenes Nacionales de Depósito, S. A. (ANSA) contabilizó 1372.3 millones de pesos, es decir el $67.5 \%$, correspondiendo el $32.5 \%$ restante a los establecimientos privados. Dado que la concentración de recursos en manos del estado queda fuera de toda duda, habremos de fijar nuestra atención sobre la distribución de los recursos de los almacenes privados.

Cuadro 16

Compañías de Fianzas (Bancarias)

Activos Totales

\begin{tabular}{ccccc}
\hline 1978 & $\begin{array}{c}\% \text { del } \\
\text { total }\end{array}$ & 1979 & $\begin{array}{c}\% \text { del } \\
\text { total }\end{array}$ \\
\hline
\end{tabular}

\section{$\underline{\text { BANCARIAS }}$}

Fianzas México Bancreser, S.A. 167479

93837

11.1

219817

10.6

Central de Fianzas, B.C.H., S.A.

210796

6.2

129200

6.2

Afianzadora Serfín, S.A.

60975

13.9

293694

14.2

Fianzas Atlas Confía, S.A.

33243

4.0

88154

4.2

Afianzadora Sofimex, S.A.

111159

2.2

54728

2.6

Cía. Mexicana de Garantías, S.A.

110671

7.3

153512

159219

7.4

Crédito Afianzador, S.A.

5.3

52.9

\section{INDEPENDIENTES}

La Guardiana, S.A.

Cía. Americana de Fianzas, S.A.

Afianzadora Mexicana, S.A.

Afianzadora Insurgentes, S.A.

Fianzas Modelo, S.A.

Afianzadora Cossío, S.A.

Cía. de Fianzas Lotonal
142769

98967

221306

74186

89695

45347

47645

3.1
47.4

178225

132961

296866

119813

108153

57762

63551

14.6

5.9

3.0

$\frac{3.1}{47.4}$
8.6

6.4

14.4

5.8

5.2

2.8

3.0

$1 5 0 8 0 7 5 \longdiv { 1 0 0 . 0 } \quad 2 0 5 5 6 5 5 \longdiv { 1 0 0 . 0 }$


El total de recursos privados ascendió en 1979 a 659.7 millones de $\operatorname{pesos}^{1 /}$, de los cuales 420.4 millones están en manos de tres almacenadoras, es decir el 64\% de los recursos privados pertenecen al $11 \%$ de los establecimientos privados en operación, además como se puede apreciar en el cuadro 17, las tres almacenadoras (Banpaís, Serfín y Comermex) están afiliadas a algún banco.

La participación bancaria en las actividades de almacenamiento no se limita a los tres establecimientos más grandes sino que comprende a un total de siete almacenadoras, mismas que controlan el $74.4 \%$ de los recursos privados, lo que se traduce en $24.2 \%$ de los recursos totales (públicos y privados).

\section{Cuadro 17}

Almacenes Generales de Depósito

Activos Totales (1979)

(Millones de Pesos)

\begin{tabular}{|c|c|c|c|c|}
\hline & Sub-tota & ivado & Total de & ector \\
\hline & Abs. & Rel. & Abs. & Rel. \\
\hline Estatales & & & & \\
\hline Almacenes Nacionales de Depósito & & & 1372.3 & 67.5 \\
\hline Privados & & 100.0 & 659.7 & 32.5 \\
\hline Bancarios & 491.2 & 24.4 & & \\
\hline Almacenadora Banpaís, S.A. & 76.3 & 11.5 & & \\
\hline Almacenadora Banpacífico, S.A. & 33.3 & 5.0 & & \\
\hline Almacenadora Serfín, S.A. & 164.0 & 24.9 & & \\
\hline Almacenadora Bancam, S.A. & 2.2 & 0.3 & & \\
\hline Almacenadora, S.A. & 180.1 & 27.3 & & \\
\hline Almacenes de Occidente & 19.6 & 3.0 & & \\
\hline Compresoras de Algodón y Bodegas & 15.5 & 2.3 & & \\
\hline Independientes & 168.5 & 24.58 & & \\
\hline Almacenes de Depósito Ocejo, S.A. & 42.8 & 6.5 & & \\
\hline Frigoríficos y Almacenes, S.A. & 10.0 & 1.5 & & \\
\hline Almacenadora Mexicana Lawrence, S.A.* & 14.9 & 2.2 & & \\
\hline Almacenes de Depósito Gómez, S.A. & 19.6 & 2.3 & & \\
\hline Almac. Grales. de Dep. El Yaqui, S.A. & 38.8 & 6.0 & & \\
\hline Almacenadora Tijuana, S.A. & 7.8 & 1.2 & & \\
\hline Bodegas Chopo, S.A. & 3.4 & 0.5 & & \\
\hline Almacenadora Veracruzana, S.A. & 1.5 & 0.2 & & \\
\hline Almac. Grales. de Dep. del Bajo Río Mayo & 7.8 & 1.2 & & \\
\hline Almacenes de Colima, S.A. & 9.4 & 1.4 & & \\
\hline Almacenes del País, S.A. & 12.2 & 1.8 & & \\
\hline S u m a: & & & 2032.0 & 100.0 \\
\hline
\end{tabular}

${ }^{1 /}$ Existe un pequeño porcentaje de error ya que diez almacenadoras pequeñas no habían reportado sus datos a la fecha que se elaboró esta nota. 
Cuadro 18

Activos totales de empresas e instituciones

Financieras por grupos**

Miles de pesos

Establecimientos Activostotales

\section{BANAMEX}

Banco Nacional de México, S.A.

107518400

Banco Provincial del Norte, S.A.

707500

Casa de Bolsa Banamex, S.A.***

1109929

Sociedad de Inversión (Segorin)

539942

Aseguradora América-Banamex, S.A.

5672437

Seguros del Pacífico, S.A.

150686

Seguros La Territorial, S.A.

444951

Hulera El Centenario, S.A.

638016

Industria de Telecomunicaciones, S.A.

1392496

Industrias H-24, S.A.

163727

John Deere, S.A.

701001

Kimberly Clark de México, S.A.

5126376

Ladrillera de Moneterrey

604411

París Londres, S.A.

1002969

Química Penwalt, S.A.

605109

Asbestos de México, S.A.

506447

Camino Real, S.A.

405035

Hotel Alameda, S.A.

97296

Celanese Mexicana, S.A.*

6968829

Cementos Apasco, S.A.*

2274908

Cía. Mexicana de Aviación, S.A.*

6281438

626147

Reynolds Aluminio, S.A.*

23820660

Fundidora Monterrey, S.A.*

2336562

IEM, S.A.*

59990297

Teléfonos de México, S.A.*

1699234

Teleindustrias Ericsson, S.A.*

2577627

199494

Lister Diesel, S.A.*

4019346

Empresas La Moderna*

210591

Industria Papelera Nacional

63771

Hipocampo, S.A.

S u ma :

\section{BANCOMER}

Casa de Bolsa Bancomer, S.A.

160639

Arrendadora Bancomer, S.A. de C.V.

Seguros Bancomer, S.A. 


Establecimientos Activostotales

Bancomer, S.A.

225281561

Frisco, S.A.

2243685

General Electric de México, S.A.

1977819

Anderson Clayton \& Co., S.A.*

2185312

1391405

109324

Prograsa de México, S.A.*

3180180

85689

Prograsa, S.A. de C.V.

539671

Sum a :

262323145

\section{SERFIN}

Banca Serfín

86136200

Banco Azteca

56000

Casa de Bolsa Serfín***

143587

Arrendadora Serfín, S.A.

1257561

Seguros Monterrey-Serfín

4711480

Afianzadora Serfín

293694

Almacenadora Serfín

164033

268078

A. C. Mexicana

515353

Fundidora de Aceros Tepeyac

604411

Ladrillera Monterrey

576801

Arrendadora Serfín

3180180

El Puerto de Liverpool, S.A.

16908617

Fomento de Industria y Comercio

38244203

Grupo Industrial Alfa, S.A.

153060198

S u m a :

\section{COMERMEX}

Multibanco Comermex

72244000

Banco Comercial Mexicano de Monterrey

1128600

Banco Comercial de Tamaulipas

1019500

Banco Comercial Peninsular

348900

Casa de Bolsa Comermex, S.A.***

184113

Sociedad de Inversión (Multifondo)

2620650

Seguros La Comercial, S.A.

4467995

Seguros La Comercial Chihuahua, S.A.

203681

Seguros La Comercial Occidente, S.A.

146181

Seguros La Comercial Puebla, S.A.

26791

Seguros La Comercial Noreste, S.A.

68329

Seguros La Comercial Norte, S.A.

188900

Seguros La Latioamericana, S.A.

656280

Almacenadora, S.A.

180147 
Establecimientos Activostotales

Industrias Purina, S.A. de C.V.

153512

Celulosa de Chihuahua, S.A.

1522048

Nacional de Drogas, S.A.

1878134

479642

S u ma:

87517403

\section{$\underline{\text { SOMEX }}$}

Banca Somex

44255000

Banco Mexicano

10840400

Banco Promex

5910100

Banco Refaccionario de Jalisco

2819000

Banco Mexicano de Occidente

1914700

Banco Mexicano de Toluca

1096900

Banco Mexicano del Golfo

990700

Banco Mexicano de Puebla

989800

Banco Mexicano del Sur

901100

Banco Mexicano del Norte

785800

Banco Mexicano del Noreste

759100

Banco Mexicano del Centro

556800

Banco Mexicano de Colima

367200

Acciones Bursátiles Somex, S.A.***

955620

Fondo de Inversiones Rentables Mexicanas (Firme)

584920

Central de Malta, S.A.

957264

Cervecería Moctezuma, S.A.

7105896

542557

Sosa Texcoco, S.A.

2206634

Vehículos Automotores Mexicanos

837885

Sanborns Mexicana, S.A.*

85377376

S u m a :

\section{$\underline{\text { ATLANTICO }}$}

Banco del Atlántico

16909200

347400

465515

Seguros del Atlántico, S.A.

32154

Casa de Bolsa del Atlántico, S.A.***

660627

Fondo Industrial Mexicano, S.A.

6441429

Empresas Tolteca de México, S.A.

24856325

S u m a : 
El Palacio de Hierro, S.A. Activostotales

Industrias Peñoles, S.A.

1483184

11937248

S u ma :

31148751

\section{$\underline{\text { CONFIA }}$}

Banca Confía

10485800

Banco Confía del Sur

684700

Banco Confía de Tamaulipas

622600

Banco Confía de Sinaloa

582600

Proveedora de Medicamentos

203967

Vehículos Automotores Mexicanos

2206634

Bicicletas de México, S.A.

222638

S u ma:

15008939

\section{SOFIMEX}

Banco Sofimex

Afianzadora Sofimex

Motores y Refacciones, S.A.

1075174

Petrocel, S.A.

3087355

S u m a :

8567851

\footnotetext{
* Accionista tomado de 1978 y activos de 1979 (BMV)

** El grado de vinculación puede variar considerablemente de un establecimiento a otro. El listado no es tampoco comprensivo.

*** Estas instituciones presentan variaciones muy fuertes de corto plazo en sus activos totales. Lo cual se debe al giro peculiar de sus operaciones con valores.

FUENTE: Anuario Financiero Bursátil, BMV.

Boletín Mensual de Indicadores y Estados Financieros de las Instituciones de Crédito. CNBS.

Informe Anual Banamex, Comermex, Somex, Atlántico y Serfín.
} 
BANCO DE MEXICO, S.A.

SUBDIRECCION DE INVESTIGACION ECONOMICA

Serie de Documentos de Investigación

1. ESTRUCTURA FINANCIERA Y EXPERIENCIA CAMBIARIA: MÉXICO 1954-1977. Guillermo Ortiz. Octubre, 1978.

2. EL FINANCIAMIENTO DEL GASTO PÚBLICO EN UNA ECONOMÍA EN CRECIMIENTO: EL CASO DE MÉXICO.

Alain Ize. Noviembre, 1978.

3. ALGUNOS ASPECTOS DEL ENDEUDAMIENTO PÚBLICO EXTERNO EN MÉXICO. Ernesto Zedillo. Diciembre, 1978.

4. UNA APLICACIÓN DEL MODELO BAYESIANO DE DECISIÓN EN EL ANÁLISIS DE FUNCIONES DE PRODUCCIÓN AGRÍCOLA.

Héctor E. González Méndez. Diciembre, 1978.

5. POLÍTICA MACROECONÓMICA EN EL CORTO PLAZO: UNA RESEÑA. Alain Ize. Marzo, 1979.

6. ESTUDIOS DE MONEDA Y BANCA Y POLÍTICA MONETARIA SOBRE MÉXICO: SELECCIÓN BIBLIOGRÁFICA DE 1943 A 1978. Abril, 1979.

7. COMERCIO EXTERIOR MÉXICO-ESTADOS UNIDOS: PROBLEMAS DE COMPARABILIDAD ESTADÍSTICA.

Jorge Carriles Rubio. Mayo, 1979.

8. EXPLOTACIÓN ÓPTIMA DE RESERVAS PETROLERAS EN UN CONTEXTO MACROECONÓMICO.

José Córdoba. Mayo, 1979.

9. ASPECTOS DEFLACIONARIOS DE LA DEVALUACIÓN DEL PESO MEXICANO DE 1976. José Córdoba y Guillermo Ortiz. Mayo, 1979.

10. EXPORTACIÓN ÓPTIMA DE PETRÓLEO Y ENDEUDAMIENTO EXTERNO: EL CASO DE MÉXICO.

Ernesto Zedillo. Junio, 1979.

11. IMPUESTOS DIRECTOS: PROGRESIVIDAD ÓPTIMA.

Jesús Seade. Septiembre, 1979.

12. OPCIONES DE POLÍTICA ECONÓMICA 1979-1982.

Sócrates Rizzo y Leopoldo Ortiz. Septiembre, 1979. 
13. INTERMEDIARIOS FINANCIEROS Y MERCADOS IMPERFECTOS DE CAPITAL. Guillermo Ortiz. Septiembre, 1979.

14. ESTIMACIONES DE EQUILIBRIO GENERAL DE LOS EFECTOS DE LAS DISTORSIONES EN LOS MERCADOS DE FACTORES: EL CASO DE MÉXICO. José J. Sidaoui y Richard H. Sines. Octubre, 1979.

15. UN ANÁLISIS DE LA INFLACIÓN EN MÉXICO. Alain Ize. Octubre, 1979.

16. ANÁLISIS DE LOS COMPONENTES DEL CAMBIO ESTRUCTURAL CON UN MODELO DE EQUILIBRIO GENERAL, 1950-75.

José J. Sidaoui y Richard H. Sines. Enero, 1980.

17. TIPOS DE CAMBIO FLOTANTES Y DESLIZ CAMBIARIO: LAS EXPERIENCIAS DE ALGUNOS PAÍSES EN DESARROLLO.

Guillermo Ortiz y Leopoldo Solís. Enero, 1980.

18. UN MODELO DE INFLACIÓN Y CRECIMIENTO EN UNA ECONOMÍA CAPITALISTA EN DESARROLLO.

Alain Ize. Enero, 1980.

19. CRECIMIENTO E INFLACIÓN: ALTERNATIVAS CAMBIARIAS PARA MÉXICO.

Guillermo Ortiz y Leopoldo Solís. Febrero, 1980.

20. COMPORTAMIENTO DE LA CAPTACIÓN BANCARIA EN MEXICO.

Héctor E. González Méndez. Mayo, 1980.

21. LA ENCUESTA DE TURISMO RECEPTIVO. REPORTE METOLOLÓGICO. Alberto Vargas Aguayo. Junio, 1980.

22. AJUSTE ESTACIONAL DE UNA SERIE DE TIEMPO MEDIANTE EL USO COMPLEMENTARIO DE MÉTODOS TRADICIONALES Y LA TÉCNICA DE BOX-JENKINS. Gabriel Vera Ferrer y Víctor M. Guerrero. Julio, 1980.

23. DISTRIBUCIÓN DEL FINANCIAMIENTO OTORGADO POR EL SISTEMA BANCARIO MEXICANO A LA BANCA PRIVADA Y MIXTA.

Víctor M. Guerrero y Gabriel Vera Ferrer. Julio, 1980.

24. LA MIGRACIÓN INDOCUMENTADA A ESTADOS UNIDOS: UN NUEVO ENFOQUE. Juan Díez Canedo. Julio, 1980.

25. UN MODELO FINANCIERO DE DESEQUILIBRIO A CORTO PLAZO PARA LA ECONOMÍA MEXICANA.

Alain Ize. Julio, 1980.

26. ESTIMACIÓN DE LA FUNCIÓN DE IMPORTACIONES PARA MÉXICO.

Javier Salas. Agosto, 1980. 
27. UNA ALTERNATIVA PARA LA MEDIA ARITMÉTICA EN EL CÁLCULO DE PROMEDIOS SIMPLES DE RELATIVOS DE PRECIOS: LA MEDIA GEOMÉTRICA.

Gabriel Vera Ferrer y Víctor M. Guerrero. Agosto, 1980.

28. LA DEMANDA DE DINERO EN MÉXICO: PRIMERAS ESTIMACIONES.

Guillermo Ortiz. Septiembre, 1980.

29. ECONOMÍAS DE ESCALA Y CONCENTRACIÓN BANCARIA: EL CASO DE MÉXICO. Héctor E. González Méndez. Octubre, 1980.

30. LA ESTABILIDAD DE LA DEMANDA DE DINERO EN MÉXICO.

Guillermo Ortiz. Noviembre, 1980.

31. EL TAMAÑO DE LA FAMILIA Y LA DISTRIBUCIÓN DEL INGRESO EN MÉXICO: UN ENSAYO EXPLORATORIO.

Gabriel Vera Ferrer. Diciembre, 1980.

32. PROMEDIOS PARAMÉTRICOS: SU SELECCIÓN Y EMPLEO EN LA DETERMINACIÓN DE ÍNDICES DE PRECIOS.

Víctor M. Guerrero. Enero, 1981.

33. UNA APLICACIÓN DEL ANÁLISIS DE INTERVENCIÓN A SERIES DE TIEMPO DE LA ECONOMÍA MEXICANA.

Víctor M. Guerrero y Gabriel Vera Ferrer. Marzo, 1981.

34. ALGUNOS ASPECTOS DE LA CONCENTRACIÓN EN EL SISTEMA FINANCIERO MEXICANO.

Héctor E. González Méndez. Marzo, 1981. 